Portland State University

PDXScholar

$11-4-1994$

\title{
Language Learning Strategies of Russian-Speaking Adult ESL Learners
}

Minerva E. Renee Kalenandi

Portland State University

Follow this and additional works at: https://pdxscholar.library.pdx.edu/open_access_etds

Part of the Bilingual, Multilingual, and Multicultural Education Commons Let us know how access to this document benefits you.

\section{Recommended Citation}

Kalenandi, Minerva E. Renee, "Language Learning Strategies of Russian-Speaking Adult ESL Learners" (1994). Dissertations and Theses. Paper 4766.

https://doi.org/10.15760/etd.6650

This Thesis is brought to you for free and open access. It has been accepted for inclusion in Dissertations and Theses by an authorized administrator of PDXScholar. Please contact us if we can make this document more accessible: pdxscholar@pdx.edu. 
THESIS APPROVAL

The abstract and thesis of Minerva E. Renée Kalenandi for the Master of Arts in T.E.S.O.L. were presented November 4, 1994, and accepted by the thesis committee and the department.

COMMITTEE APPROVALS:

DEPARTMENT APPROVAL:

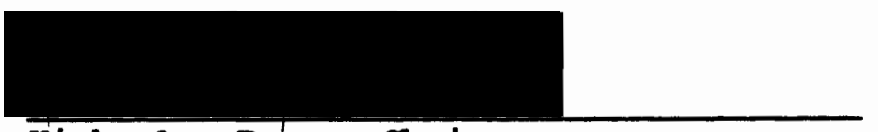

$$
\text { Kimberley Brown, Chair }
$$
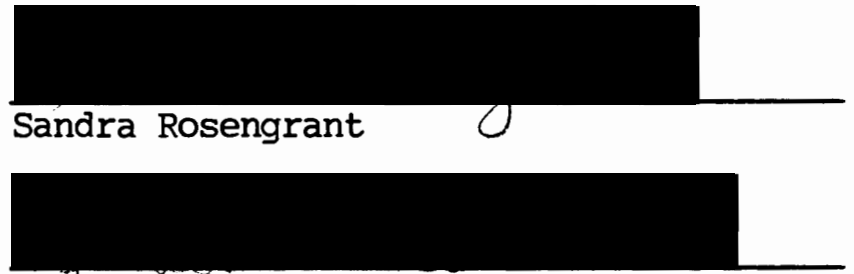

Jeánnette DeCarrico

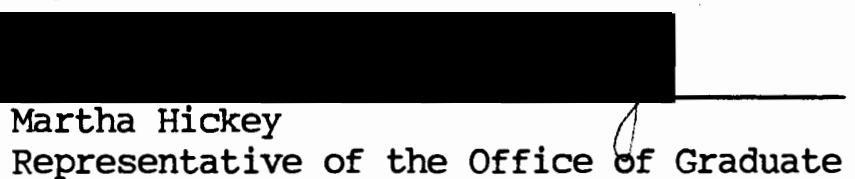
Representative of the Office of Graduate Studies

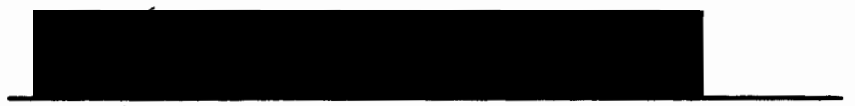

Beatrice Oshika, Chair

Department of Applied Linguistics

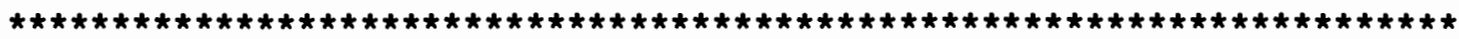

ACCEPTED FOR PORTLAND STATE UNIVERSITY BY THE LIBRARY

by

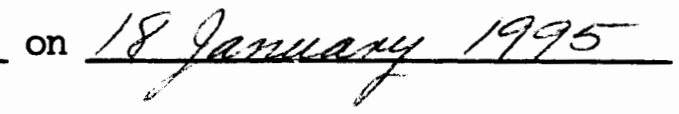


An abstract of the thesis of Minerva E. Renée Kalenandi for the Master of Arts in T.E.S.O.L presented November 4, 1994.

Title: Language Learning Strategies of Russian-Speaking Adult ESL Learners.

In the ESL classroom, there are often cultural differences between learners and teachers. Sometimes these differences can lead to misunderstandings or even conflict. One area where differences between cultures can be seen is language learning strategies and styles. This study explores the possibility that awareness of differences, explicit teaching, and negotiation may help to resolve differences.

This study looks at differences between Russian-speaking adult ESL learners and American ESL teachers, with respect to strategy use and preferences. Three aspects are investigated. The first is to see whether there are statistically significant differences between these groups of learners and teachers. The second is to try to form a loose profile of the learners as a cultural group. The third is to see whether or not there is evidence to suggest the validity of explicit teaching of strategies in the ESL classroom.

The Strategy Inventory for Language Learners (SILL), developed by Rebecca Oxford, is one way to assess differences between learners and teachers. A survey including the SILL and a questionnaire was given to 
ninety-four subjects. Forty-seven are Russian-speaking adult ESL learners and forty-seven are American-English-speaking ESL teachers or potential ESL teachers taken from a TESOL program.

The results of the survey show that, in this case, there are statistically significant differences in preferences for and use of several sets of strategies. A preliminary cultural profile is derived from the SILL results and from anecdotal evidence gathered from the questionnaire. There is some evidence that the explicit teaching of language learning strategies and their use may help resolve some of the classroom conflicts between the two groups studied. 
LANGUAGE LEARNING STRATEGIES OF

RUSSIAN-SPEAKING ADULT ESL LEARNERS

by

MINERVA E. RENEE KALENANDI

A thesis submitted in partial fulfillment of the requirements for the degree of

MASTER OF ARTS

in

T.E.S.O.L.

Portland State University

1994 


\section{ACKNOWLEDGEMENTS}

I would like to acknowledge the help and support I received from so many people during the course of my studies. I would like to thank Pat and Frodo and the women of SisterSpirit, for supporting me spiritually, emotionally, and sometimes financially, during this travail. Special thanks go to Astarté, for many sanity checks and games of chinese checkers, and especially for the cookies. Thanks also to my parents, for their endless queries of "Aren't you done with that thing yet?" and for help with transportation (i.e. the "SS Behemoth").

I would also like to acknowledge and thank those directly involved with my work on this thesis. They include my advisor, Kim Brown, thesis committee readers Sandra Rosengrant (who also helped to proofread my Russian typing!), Marge Terdal, and Jan De Carrico. I also appreciate very much the help of Stephaine Taylor, at Voc-Rehab, who helped with most of the financial aspects, as well as the teachers who allowed me access to their students. And special thanks to Rebecca Oxford, who not only developed the SILL, but sent me a copy of the Russian version before it was even typed!

But most of all, I thank the Goddess, for getting me through it all- physically, mentally, financially, and finally. Blessed Be. 
TABLE OF CONTENTS

PAGE

ACKNOWLEDGEMENTS............................ i i

LIST OF TABLES............................ vi

LIST OF FIGURES............................ vii

INTRODUCTION................................ 1

Statement of the Problem....................... 1

Background............................... 2

Culture and Language Learning

Theoretical Background

Definition of Terms......................... 4

Styles and Strategies

Culture

Profile

Russian-Speaking

Research Questions........................... 6

Method.................................

REVIEW OF THE LITERATURE...................... 8

Introduction. ............................ 8

Language Learning Strategies and Learning Styles...... 9

Language Learning Strategies

Learning Styles

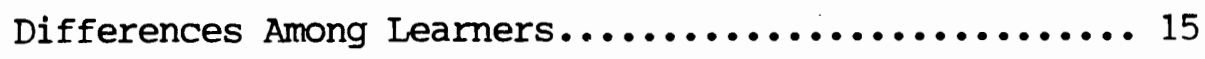

Factors Relating to Differences

Importance of Differences 
Culture, Styles, and Strategies................. 18

General Definition of Culture

Culture and ESL

Resolving Conflicts

Summary

An Example of Culture Conflicts in the Classroom..... 24

Overview

Cultural Values and Experiences in the USSR

The Soviet Education System

Classroom Conflicts as an Example of Culture

Conflicts

Summary

METHOD...................................... 33

Introduction............................ 33

Methodology ............................... 34

Variables

Subjects

Sampling

Composition

Instrument

Statistical Procedures.

Data

Statistical Procedures

Anecdotal Information...................... 49

Overview

Target Group

Comparison Group

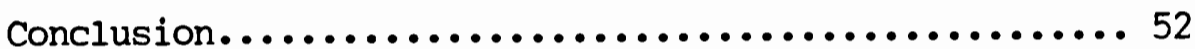

RESULTS.................................. 54

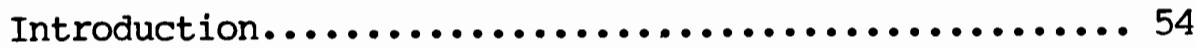

Significant Differences

Strategy Profile

Validity of Explicit Teaching 
Results................................ 56

Composition

Basic Statistics

ANOVA

Results

Conclusion...............................66

DISCUSSION........................................... 67

Introduction........................... 67

Discussion of Significant Findings............. 68

Cognitive Strategies

Metacognitive Strategies

Affective Strategies

Social Strategies

Summary

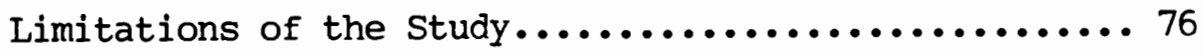

Data Collection

Data Analysis

Scope

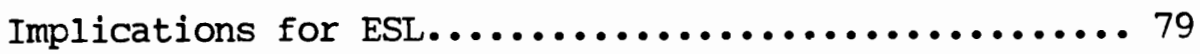

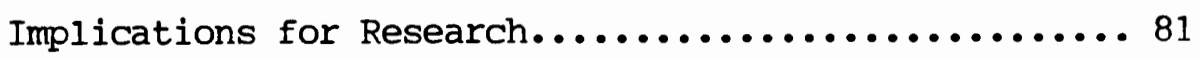

REFERENCES.................................. 83

APPENDICES

A SURVEY : ENGLISH VERSION.................. 88

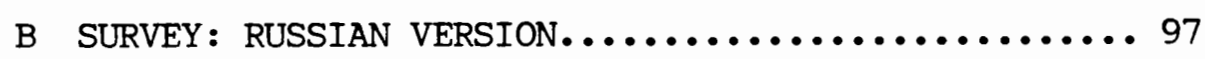

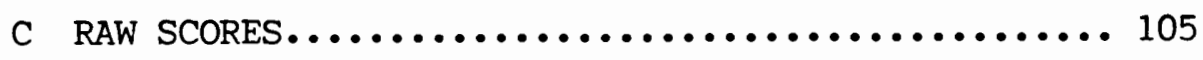

D LANGUAGE LEARNING STRATEGIES............... 110 
LIST OF TABLES

TABLE

PAGE

I Response Rate for Target Population........... 37

II Response Rates for Comparison Group............ 38

III Response Rates for Target Population and

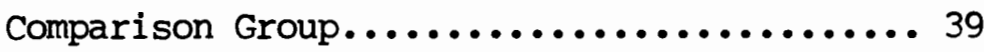

IV Composition of Target and Comparison Groups,

By Language....................... 40

V Composition of Target and Comparison Groups,

By Gender.......................... 41

VI Composition of Target and Comparison Groups,

By Age.......................... 42

VII Composition of Groups, By Age Groups........... 43

VIII Composition of Groups, By Education............ 44

IX Basic Statistics, By Language Groups........... 58

X Basic Statistics, By Gender................ 58

XI Basic Statistics, By Education.............. 59

XII ANOVA Results........................... 61 


\section{LIST OF FIGURES}

FIGURE

1. Various Taxonomies of Language Learning

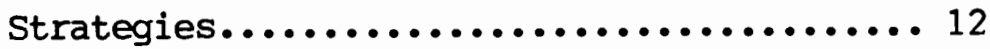

2. Various Language Learning Styles............. 16

3. Summary of Statistically Significant Results,

Where $*=.05$ Probability; $* *=.01$

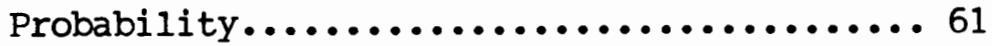


CHAPTER I

\section{INTRODUCTION}

STATEMENT OF THE PROBLEM

Many factors contribute to learners' strategy preferences. One of the most important is culture. Culture helps determine personality type and cognitive style (Evans, 1987). The education system of a culture fosters the selection and use of certain strategies (Peck, 1991). When an ESL teacher from one culture teaches learners from another, there is often a mismatch of styles and strategies. One way to prevent problems that could arise from such a mismatch is awareness of preferred strategies of both learners and teachers. Since it is not feasible in many ESL programs to test every learner, it would appear to be beneficial to establish style and strategy profiles of cultural groups of learners. This would prepare teachers to deal with mismatches before they can become problems in the classroom. Many differences will still appear as a function of individual variation, but those that are associated with a culture group may help teachers to be more effective in the ESL classroom. It is important to $100 \mathrm{k}$ at the profile as a general guideline and to avoid stereotyping and over-generalizing. 
BACKGROUND

\section{Culture and Language Learning}

The topic of the influence of culture on language learning strategies is interesting for several reasons. The first of these is my own experiences as a teacher in classrooms where several language and cultural groups are represented. One of the main concerns in developing lessons, activities, and materials is taking into consideration the existing styles and strategy preferences of learners. While individual differences were present, it often seemed that members of the same language or cultural group were more alike in their cognitive styles and language learning strategy preferences. Differences in the ways that teachers were teaching and the ways that learners were learning seemed to cause friction at times in the classroom. If teachers were more aware of how their learners were thinking, and how aspects of their cultures affected the ways that they learned, it would be easier to effect a compromise in styles and strategies utilized in the classroom, and to explicitly discuss and teach strategy use.

A specific population, Russian-speaking adult ESL students, was chosen for several reasons. The first is an ongoing interest on the part of the researcher in the contrasts between Eastern European and Soviet culture and that of the United States, especially in the area of education and psychology. Another was the researcher's familiarity with the group through ESL teaching and other contexts. The third consideration was simply availability. Russian speakers comprise one of 
the largest groups in beginning ESL programs in the Portland area (Levinsky and Rubinstein, 1994).

\section{Theoretical Background}

Current ESL research acknowledges and even stresses the importance of language learning strategies and styles in the processes of learning and teaching. One of the earlier investigations of the importance of strategies to language learning and teaching is the model of the Good Language Learner. This model is comprised in large part of a list of strategies that are engaged in by successful learners (Naiman, Frolich, Todesco, and Stern, 1978). Oxford's (1990) taxonomy of strategies is one of the most comprehensive. It includes a number of specific activities, general processes, and sets of strategies. A more recent discussion of the Good Ianguage Learner model, strategy use, and implications for language teaching can be found in Oxford, Lavine, and Crookal1 (1989).

Learner styles affect which strategies are chosen and used by learners. Styles are habits of thinking and perceiving, while strategies are habits of learning and doing. Lono (1987) suggests the following continuum: variables influence styles, which influence selection and use of strategies, which influence the learning process. Maurice's (1986) view is that culture can determine which styles and strategies are used because the norms of learning behaviors and attitudes are determined by culture.

Because of this connection between culture and learning, it is important to recognize diversity, and to assess the style and strategy 
profiles of both learners and teachers. Evans (1987) advises a 'cultural diagnosis', to find out what learners know, what prior educational experiences they have had, what the preferred styles and strategies of the culture are, and the attitudes and expectations of the learners. The means of assessing diversity could include surveys, polls, or scales for a quantified assessment, as well as student logbooks or discussions (Peck, 1991). The purpose of the proposed study is to provide a preliminary cultural diagnosis of one culture group in a specific context.

DEFINITION OF TERMS

\section{Styles and Strategies}

Language learning strategies are defined by Rebecca oxford as "operations employed by the learner to aid the acquisition, storage, retrieval, and use of information" (Oxford, 1990, p.8). These strategies are specific activities related to the direct or indirect processes of learning. Learning styles, on the other hand, are defined by Skehan as "... a general predisposition, voluntary or not, toward processing information in a particular way" (Skehan, 1991, p.288). In other words, cognitive or learning styles are general modes or patterns of thinking. Certain strategies or styles may make the learning process more difficult, or make specific learning or communicative tasks easier for some people than for others. Effective use of strategies leads to a more effective learning experience. 


\section{Culture}

Different researchers have made varied suggestions as to which factors relating to variation among learners should be considered part of culture. Since this study is not looking at specific cultural variables, but rather culture itself as a variable, the term "culture" will be presumed to be the collective characteristics of a group that shares the same background knowledge, language, and basic belief system, based on nation of origin. This definition is based on a combination of sources, including Evans (1987), Wardhaugh (1969), Coady (1979), Carroll (1965), Saville-Troike (1976), Lono (1987), and Maurice (1987).

\section{Profile}

The term "profile" is used in this study to replace Evans' (1987) term "cultural diagnosis". It refers to the similarities in style and strategy preferences among a given group of learners. The term "cultural diagnosis" seems to imply that the characteristics of a group of learners is somehow in need of being fixed or cured. "Profile" seems less value laden and more objective as a descriptor. A profile is a guideline and should not be taken as a stereotype of members of any given cultural group.

\section{Russian-Speaking}

The terms 'Russian-speaking' and 'Russian speaker', as used in this study, refer to culture rather than language. This term was chosen because it seemed to express the commonality of cultural and 
educational experience in the former Soviet Union. The target group was comprised primarily of evangelical and pentecostal Russians and Ukrainians. Since the target group includes persons from different ethnic groups, but similar backgrounds, a term was needed that included all of the respondents. The term 'Russian' is inappropriate to describe persons other than ethnic Russians. The term 'evangelical and pentecostal Russians and Ukrainians' is impractical and much too long. All of the respondents were from the former Soviet Union and had the shared experiences of the standardized Soviet education system. All of the surveys used in this study were from respondents who gave Russian as a first language, either exclusively or with Ukrainian. Because of these factors, 'Russian-speaking' and 'Russian speaker' were deemed to be the most appropriate and the most practical ways of describing the target group. These terms refer only to the specific respondent group in this study.

RESEARCH QUESTIONS

This study examines the following set of questions:

A. Is there a significant difference between the learning strategies of ESL teachers in the U.S. and those of Russian-speaking learners in ESI programs in the U.S.?

B. What is the strategy profile of Russian speaking refugee ESL learners? 
C. Does the available evidence show that there is a valid reason for explicitly teaching language learning strategies?

The related hypothesis and null hypothesis tested during the course of this study are as follows:

$\mathrm{H}_{1}$ Significant differences between the two groups exist with regard to the scores on one or more portions of the SILL. $\mathrm{H}_{\mathrm{O}}$ Significant differences do not exist between the two groups with regard to scores on any portion of the SILL.

METHOD

In order to investigate possible answers to the research questions this study provides a preliminary cultural profile of strategy use for Russian-speaking adult ESL learners in the Portland area. It compares the profile of this group to the profile of the comparison group of ESL teachers and potential ESL teachers, using ANOVA. The instrument used in this study is a survey. This survey includes the Strategy Inventory for Language Learning developed by Rebecca Oxford (1990) and a questionnaire relating to demographic information and educational background, based on the questionnaire accompanying the SILL. (Oxford, 1990). It also contains open-ended questions on observed differences between the profiles of learners and teachers, and between educational systems of the target population and their teachers in the U.S. 
CHAPTER II

REVIEW OF THE LITERATURE

INTRODUCTION

The importance of looking at learning strategies and styles is based on the process orientation rather than the view of language learning as a product. This orientation 100ks at how students learn, the steps involved in learning, and the roles of various activities and interactions involved in learning (Wright, 1987). The process orientation is in opposition to input-output approaches, which are based on the notion that learning is a concrete product produced by exposure to appropriate input (i.e. teacher discourse, texts, audio and video tapes) (Brown, 1987). It focuses on the learner's responsibility for learning. Examining strategies and styles of learning is a way to look explicitly at ways that learners think, and how they process information. It is also a way to look at the specific tasks learners engage in during the process of learning. The examination of styles and strategies provides a way to find out which patterns of strategies and styles lead to more effective learning. This can lead to a more appropriate methodology of language teaching, based on the ways learners do learn. It also can lead to figuring out which strategies 
can be taught to help learners be more effective in achieving their goals and fulfilling their needs. Making learners aware of styles and helping them to look at different ways of thinking and perceiving can also be a part of a more appropriate language teaching methodology.

Four general questions will be addressed in this discussion of the impact of culture on the selection and implementation of learning strategies and styles during the process of language learning and acquisition. The first of these concerns the specific strategies and styles that have been identified and researched. The second investigates the factors that account for variation among individuals. Third, the cultural aspect of variation in learning strategies and styles is examined. Finally, an example of how the differences between cultures can result in conflicts in the classroom is considered.

LANGUAGE LEARNING STRATEGIES AND LEARNING STYLES

\section{Ianquage Learning Strategies}

General Definitions. As previously mentioned in Chapter One, strategies are usually presented in terms of a taxonomy or a list of activities engaged in during the process of learning. One of the first models of strategy use was the model of the Good Ianguage Learner, which pointed out a list of successful learning behaviors or habits that language learners engaged in (Naiman et al, 1978). According to Naiman et al (1978), the Good Language Learner approaches learning as an active task and sees language as a system. He or she recognizes and uses the target language as a means of communication and interaction. A 
good language learner deals effectively with affective aspects of language learning and monitors target language use.

Skehan (1989) refers to Wong-Fillmore's investigation of children's language learning strategies. Her taxonomy is fairly simple, and is based on the self-reports of the children she worked with. Her set of strategies includes social strategies such as joining a group and talking to friends in the target language. Cognitive strategies are also included, such as pretending to understand the target language, until the learner is able to figure out the message.

Taxonomies. O'Malley, Chamot, Stewner-Manzares, Kupper, and Russo (1985) proposed a set of strategies that included metacognitive, cognitive, and social strategies used in the process of learning and acquisition of a language. Tarone (1983) proposed a set of communication strategies, including paraphrase, borrowing and avoidance as categories. She gives examples of activities as specific strategies. The set of strategies referred to by Tarone (1983) specifically deals with the ways in wich learners compensate for missing or insufficient knowledge in the target language. Other discussions of strategies can be found in Faerch and Kasper's Strategies in interlanguage communication (1983).

Oxford (1990) includes some of the above strategies in her taxonomy. She lists them under the heading compensation strategies. This taxonomy, which is one of the most comprehensive, includes over sixty specific activities. These are subdivided into nineteen general processes and six sets of strategies. The direct strategies are those dealing with memory, cognition, and ways of compensating. Indirect 
strategies include those concerned with metacognitive, affective, and social factors (1990).

Specific examples of mnemonic strategies are word grouping and categorization, word associations, use of imagery, and reviewing. Examples of cognitive strategies are practising, receiving and sending messages in the target language, translating, and transferring knowledge from one language to another. Compensation strategies include using cues and clues, asking for clarification, avoidance, and paraphrasing. Specific metacognitive strategies include planning learning tasks, setting goals and objectives, and self-monitoring. Examples of affective strategies are relaxation techniques, self-encouragement, awareness of feelings, and stress checklists. Social strategies include asking for clarification or correction, cooperating with peers or others, and developing understanding of others (Oxford, 1990). For a more detailed list of specific strategies, see Appendix D, page 110, or Oxford (1990), Lanquage learning strategies: What every teacher should know. Oxford, Lavine, and Crookall (1989) present a condensed version of this taxonomy. They also include a discussion of implications for language teaching. Many of these taxonomies and descriptions of language learning strategies show a lot of overlap. Figure 1 (p.12) shows how the different descriptions and classifications compare. The common factors in these discussions are the focus on language learning and acquisition as a process and the importance given to the learner's responsibility for the process. In general, the types of strategies do not conflict with one another. Differences are found mainly in the 
Oxford (1990)

Naiman et al

O'Malley et a1

Wong-Fillmore

(1976, in

Others

$$
\text { (1978) }
$$

(1985)

$$
\text { Skehan, 1989) }
$$

DIRECT STRATEGIES

$$
\text { Memory }
$$

Cognitive

$$
\begin{gathered}
\text { Ianguage as } \\
\text { System }
\end{gathered}
$$

Cognitive

Compensation

\begin{tabular}{|c|c|c|c|c|}
\hline Metacognitive & Monitoring L2 & Metacognitive & & \\
\hline Affective & $\begin{array}{c}\text { Managing Affective } \\
\text { Demands }\end{array}$ & & & \\
\hline Social & $\begin{array}{c}\text { Language as a Means } \\
\text { of Communication/ } \\
\text { Interaction }\end{array}$ & Social & Social & Task-Based \\
\hline
\end{tabular}

Active Task Approach; Language as a Means of

Communication/interaction

INDIRECT STRATEGIES

Fiqure 1. Various taxonomies of language learning strategies.

( C) Kalenandi 1994) 
scope of the discussions, the degree of detail, and the aspects covered-i.e. cognitive, compensation, affective. Skehan (1989) points out some important features of strategy-based approaches. He says that social strategies are the most important strategies in informal learning. The more exposure a learner has to the target language and the more a learner interacts with others in the target language, the more he or she has opportunities for learning and acquisition. Social strategies are concerned with the time spent learning. Furthermore, the reflective strategies, or metacognitive and cognitive strategies, are important to all but the youngest learners. According to Skehan (1989), The major focus of strategy-based approaches is on viewing language as a system rather than relying on formulaic learning.

\section{Learning Styles}

General Definitions. While strategies are specific processes and activities, cognitive and learning styles are orientations or preferences for certain ways of thinking about, perceiving, and organizing information. These styles are often presented in opposing pairs of traits and are measured on a continuum. A person's learning style is described as an orientation towards or preference for one or the other of the traits in a dyad. Richmond (1987) defines styles as leading to expectations and responses of learners. Some of the parameters she discusses are preferences for individual or group learning. Others relate to indirect or direct styles of interaction. Maurice (1986) examines the axis of inductive-deductive-affective reasoning orientation. Inductive thinkers tend to make hypotheses, then 
10ok for evidence to support or disprove them. Deductive thinkers look at evidence, and then draw conclusions. Affective thinkers tend to make decisions based on how they feel about a subject (1986). Iono (1987) looks at styles as ways of organizing information, expressed in thought patterns and discourse structures. These would indicate a preference for explicit or implicit styles. These styles are reflected by circular, linear, or other discourse patterns. Explicit thinkers tend to be direct and focused on specific information. Implicit thinkers tend to work around specifics, by going into detail, restating, or giving examples or analogies (Lono, 1987).

Peck (1991) discusses several aspects of learning styles. These aspects include orientations towards individual, small group, or large group learning situations, towards visual or audio learning, and towards observation or participation as a means of learning. Types of learning, such as analysis and exploration of rules, translation, and rote learning, are examined as we11. Skehan (1989, 1991) gives 1istings of some of the most widely investigated styles. One of the most important is field independence/dependence. A field independent learner can look at information in an objective way, without relying heavily on context, while field dependent learners need a lot of context to process information. Other styles include introversion/ extroversion, analytic learning/formulaic learning, and levels of risk-taking (Skehan, 1989). Other orientations include preferences for visual, audio, or kinesthetic modes of learning, and active/passive learning (Skehan, 1991). One more range of styles is external/internal locus of control, which relates to how learners make attributions (see Roberts, 
1992; Roberts and Iocke, 1991). For a comparison of style descriptions, see Figure $2(p .16)$.

When considering cognitive and learning styles, it is important to remember that the measurements or orientations are not absolute. For each axis there exists a continuum. Most learners exhibit a mix of orientations and preferences for any of the styles. Styles also can affect which strategies are chosen and used by learners. A learner with strong orientations towards introversion, individual learning, and observational learning, for example, would be less likely to rely heavily on social strategies. Strategies are habits of learning and doing, while styles are habits of thinking and perceiving.

\section{DIFFERENCES AMONG LEARNERS}

\section{Factors Relating to Differences}

Individual differences among language learners are found for a number of reasons. The basic concept of individual differences is that a learner's particular perspective, experiences, abilities, and motivations lead to a unique profile of language learning. Many factors related to individual differences among learners have been proposed by various researchers. In general, there seem to be three kinds of factors. The first kind are those that are immutable, or beyond control-i.e. age, gender, intelligence. The second kind are those that are due to factors wich can be modified or negotiated-i.e. educational factors, cultural factors, social factors. Third, there are 
Field Dependent/ Independent

Introversion/ Extroversion

Analytic/

Formulaic

Analytic v.

Translation $v$.

Rote Learning

Risk Taking

$\begin{array}{cc}\begin{array}{c}\text { Visual/Audio/ } \\ \text { Kinesthetic }\end{array} & \text { Visual/Oral } \\ \text { Active/Passive } & \begin{array}{l}\text { Observation/ } \\ \text { Participation }\end{array}\end{array}$

Individual/Sma11 Group/Individual/Group

Iarge Group

Internal/External

Locus of Control

$\begin{array}{lr}\text { Implicit/ } & \text { Direct/ } \\ \text { Explicit } & \text { Indirect }\end{array}$

Inductive/Deductive/

Af fective

Figure 2. Various language learning styles.

(C) Kalenandi 1994) 
those that are solely within the control of the learner-i.e. motivation, attitudes, cognitive style.

In the Good Language Learner model, three sets of factors are sorted out. The first set is comprised of teaching factors. These include materials, syllabus, methods, and resources available. The second set pertains to factors which are intrinsic to the learner. This set includes age, intelligence, aptitude, motivation, personality, and cognitive style. The third relates to contextual factors. These include ducational setting, opportunities for use, and social milieu (Naiman et al, 1978). Carroll's model (1965) is based on factors which govern interaction in formal learning. A differentiation is made between instrumental factors, such as time, setting, and instructor's ability, and individual factors, such as intelligence, aptitude, and motivation.

\section{Importance of Differences}

Patterns. Individual differences between learners are important because examining the variables connected to differences can point out patterns. These patterns can be investigated for causality. Possibly, some factors could be manipulated or negotiated for more effective learning and teaching. Relationships between styles and strategies could be established or explained by looking at relationships between the variables related to differences. If relationships between factors, strategies and styles can be identified, the teaching of languages can be adapted to the needs of groups or individuals for the most effective learning experience. 
CULTURE, STYLES, AND STRATEGIES

\begin{abstract}
"In the classical anthropological sense, culture refers to the cumulative deposit of knowledge, beliefs, values, religion, customs, and mores acquired by a group of people and passed on from generation to generation... It is also communicable knowledge, learned behavioral traits that are shared by participants in social groups and manifested in their institutions." (Harris and Moran, 1979, in Nayar, 1986, p.2)
\end{abstract}

\title{
General Definition of Culture
}

There appear to be as many definitions of culture as there are researchers studying culture or aspects of culture. Evans (1987) sees ethnicity, personality, education, attitudes, and gender and age roles as cultural factors. Wardhaugh (1969) proposes that culture is contextual and pragmatic knowledge. Using these definitions, any factor which relates to context or use of language could be a cultural variable. Some researchers propose that culture is comprised of background knowledge, strategies, and conceptual and perceptual styles (Coady, 1979; Carroll, 1965; Saville-Troike, 1976). Lono (1987) goes

further and links cultural factors to those which contribute to the learner's schema. Maurice (1986) sees culture as a filter for determining which pieces of incoming information are important. According to Maurice (1986), culture also guides the interpretation of received input. He also sees culture as a base for 'common sense', which designates right and wrong ways of thinking, perceiving and doing. 
Culture and ESL

Conflicts. Why is it important to look specifically at cultural variables related to differences between learners? In the field of language teaching, especially English as a Second Language (ESL), teachers and learners are often, if not usually, from different cultures. One of the most important ramifications of this is the development of intercultural conflicts. When a teacher in the classroom is teaching according to his or her cultural pattern of styles and strategies, there is the possibility of conflict. Ignoring, or worse, devaluing, the cultural patterns of learners, can lead to an even greater potential for conflict. Maurice (1986) indicates that cultural norms lead to learner and teacher attributions. His view is that culture can determine which styles and strategies are used, through norms of learning behaviors and attitudes. Learners and teachers make attributions according to the fit between what they believe to be common sense and the information presented to them. He says that the solution is to anticipate and accept diversity in the classroom (1986). Oxford, Lavine, and Crookall (1989) suggest that the classroom implications of the need to cultivate strategy use and develop communicative competence lead to a shift in techniques, roles, and environment. Organization of the classroom needs to be learner-based and supportive of the learners' goals. Iearning needs to be task-based and centered on more realistic forms of communication. Active learning should be encouraged. Teachers should support learner creativity, problem-solving skills, and interpersonal cooperation in the classroom. They need to explicitly train learners in strategy use, so that 
learners will be aware of the strategies and have them available for use (1989). Rost and Ross (1991) also suggest the possibility of explicitly teaching communication strategies to assist learners in achieving communicative competence. They state that if the strategies used by more advanced learners can be taught to lower levels, the communicative competence of those learners could be enhanced. Teaching cultural styles and strategies. Other researchers also feel that strategies and styles can and should be taught to learners in order to facilitate the language learning process. Bentahila and Davies (1989), for example, examine how cultural knowledge, which includes strategies and styles, works in the process of learning and teaching a second languages. They also explore the extent to which styles and strategies of one culture should be recognized by and adopted by learners and teachers of a second language/culture. They conclude that the extent to which learners or teachers should adopt cultural styles and strategies depends on the purpose of learning (1989). Lennon (1990) noted that strategy use and learning styles are more important to development of communicative competence than just placing a learner in an L2 environment. Iennon says that if learners do not use strategies effectively, it doesn't matter where they are. They need to be able to make effective use of language opportunities to develop proficiency. Si-Qing (1990) also discusses the need for explicitly teaching specific skills and strategies to culturally different learners. 
Resolving Conflicts

Awareness of differences. Byrd (1986) suggests that awareness of the points of conflict between cultural styles and strategies is the first step towards resolving them. Teachers need to deal explicitly with the differences. They need to teach strategies and awareness of strategies. They need to adapt the curriculum to the needs of students. The first step is to recognize diversity and to assess the style and strategy profiles of both learners and teachers. Peck (1991) recommends several means of assessing diversity. These include surveys, pools, and scales, for a quantified assessment. Other means that Peck suggests are student logbooks or discussions. Evans (1987) advises a 'cultural diagnosis' to find out what learners know, what prior educational experiences they have had, what the preferred styles and strategies of the culture are, and the attitudes and expectations of the learners.

Reconciliation. The next step is to find a way to reconcile culturally different sets of styles and strategies. Since teacher and learner share and negotiate the learning process, both need to recognize the different cultures represented in the classroom. They also need and to work together to negotiate the means of the process (Gurney, 1987). The teaching of culture is always taking place in a language classroom, either explicitly or implicitly. Some researchers suggest the explicit use of cultural differences in learning as tools in the classroom. Fitch (1987) says that there is a need to dispel myths and stereotypes and to reconcile differences in learning expectations, behaviors and interaction patterns. One tool that could be used in conducting a cultural diagnosis, promoting awareness of 
variation, and reconciling styles and strategies is the Intercultural Sensitizer (ICS). Albert (1983) describes the construction and uses of ICS's. An ICS is designed to promote intercultural interaction and communication and to reduce intercultural friction. An ICS consists of examples of intercultural situations. It gives several possible options for action in each situation. These options are based on the cultural norms and expectations of the different groups involved in the situation. The examination of each situation and its possible outcomes leads to discussion and, hopefully, intercultural understanding (Albert, 1983). Perhaps it would be possible to develop an ICS relating specifically to cultural aspects of variation in styles and strategies.

Activities. Some researchers suggest specific activities to teach awareness and use of new styles and strategies. Brown (1989) discusses the use of task-based learning to develop learning and communications skills. Peck (1991) uses diversity as a springboard for discussion and activities in the classroom. Cameron and Epling's study (1989) suggested that small group and pair activities can be more effective when interaction styles of students are considered in the composition of such groupings.

Classroom culture. Furey (1986) proposes the creation of a third, intermediary, or classroom culture. This culture would explicitly deal with difference and have clearly delineated ground rules, expectations and norms for classroom behavior and process. Teacher and learners would negotiate between varying styles and sets of preferred strategies. Little and Sanders (1989) also explore the relationship between communication and community in a foreign language classroom. 
Their conclusions are that a notion of community is necessary to developing good communication skilis. Classroom community can be fostered by relating the curriculum and materials to learners' own experiences and styles of learning. In their article, they include specific ways to create a classroom community.

Testing. Cargill (1987) discusses the importance of recognizing cultural differences in learning with respect to testing issues. Besides the problem of testing that refers to cultural background, culturally different styles and strategies can lead to problems in design and accuracy of testing as well. Tests need to be constructed with cultural profiles in mind, when deciding which types of items should or should not be used. Organization of information in tests also is an area which is affected by cultural patterns of learning and thinking.

\section{Summary}

Cultural patterns of variations in language learning strategies and learning styles are important in teaching and learning language, because they can lead to conflict, ineffective implementation of teaching methods, and other problems for both teachers and learners, inside and outside of the classroom. Resolution and prevention of these problems can be accomplished. A good discussion of cultural conflicts and conflict resolution in the classroom can be found in Scarcella's Teaching language minority students in the multicultural classroom (1990). First, there is a need for awareness and anticipation of diversity. Assessment of cultural profiles of style and strategy 
preferences and use comes next. Finally, differences which could cause problems need to be reconciled. This can be done through explicitly teaching and discussing variation, negotiation, adjusting curriculum, and creating of a classroom culture.

AN EXAMPLE OF CULTURE CONFLICTS IN THE CLASSROOM

\section{Overview}

This study centered around the cultural conflicts between Russian-speaking learners and U.S. teachers in ESL classes. Russian-speakers comprise a large proportion in Portland, Oregon metropolitan area ESL classes. In Oregon, this group made up only $1 \%$ of all immigrants from 1975 to 1987 . This increased to $14 \%$ in 1988 . In 1989, immigrants from the now-former U.S.S.R. accounted for $65 \%$ of all immigrants. The figures for 1993 show that $46 \%$ of all immigrants coming to Oregon were from the former Soviet Union. Most of these were Pentecostal or Evangelical Christians from the Ukraine (Levinsky and Rubinstein, 1994). This high proportion of Russian-speakers can and does lead to conflicts in the classroom (Wiggins, 1994). These conflicts have their roots in cultural differences in values, experiences, educational practices and philosophy, and reasonable expectations based on these values, experiences and practices (Wiggins, 1994). This process also occurs for U.S. teachers who have expectations based on their own cultural experiences. 
Cultural Values and Experiences in the U.S.S.R.

Kunz (1991) stated that in the cultural characteristics of the former U.S.S.R. and the U.S. a distinct dichotomy can be found. He found that values in the U.S.S.R. centered on centralism, community, communal work, and stability. In the U.S., Kunz found that values are centered on democracy, individualism, cooperation, and innovation. Soviet values were supposed to have been based on the goals of Marxism/Leninism. These goals were to have fostered a classless society of workers and peasants, with strata determined by whether an individual performed manual or non-manual labor (Nyirady, 1991). Further, the workers and peasants were to be co-equal in authority, which was itself comprised of workers and peasants. There was to be no separate ruling class, neither elected, appointed, nor hereditary (Lenin, 1932). Lenin (1932) and the early Soviets believed that the 'classless' society would evolve through state-enforced values of atheism, cooperation and working for the common good, respect for central authority, and the view that the community is worth more than the individual.

In practice, the Soviet system was rigid, totalitarian, and extremely centralized and bureaucratic, while lip service was still paid to the original values (Iane, 1992). The values of the soviet government and the Communist Party of the Soviet Union (CPSU) were inculcated through cultural activities, political activities, the economy, all forms of media, and education, all of which were overseen by the CPSU, which controlled the central government (Nyirady, 1991). Membership in the CPSU and adherence to the principles of the Soviet 
central government were key factors in obtaining educational opportunities, social status, occupational opportunities, and privileges and benefits. Wiggins (1994) showed that the core values of Soviet society and culture were exhibited in the citizens by a desire for stability, security, social order, predictability, and an avoidance of risk. Wiggins noted that these values were also shared by groups and people who were opposed to the central authority, such as the Pentecostal and Evangelical Christians from the Ukraine who emigrated from the former U.S.S.R. to the U.S..

Experiences are also a part of culture. The experiences of the majority of the Russian-speaking immigrants in this study have an effect on the values that they hold and on their expectations. These experiences include repression of religious groups and their members, and repression of Ukrainians, whose nationalism was perceived as a threat to the central authority (Skallerup, 1991). Most of the immigrants in the Portland, Oregon metropolitan area have experienced these types of repression. There was also pressure to conform to the Soviet ideals and to belong to the CPSU, including its youth groups and other associations (Gaudiak, 1991). The results of refusal to conform were unequal opportunities in education and employment (Skallerup, 1991). The effects on the refugee population include a general antagonism towards authority and a lack of ambition in seeking both educational and occupational opportunities (Skallerup., 1991; Wiggins, 1994). 
The Soviet Education System

Characteristics. The Soviet education system was dominated by the CPSU and government ministries (Zickel, 1991). This led to the formation of a huge bureaucracy, devoted to the creation and maintenance of a centralized, standardized curriculum, with conservative methods and content (Steckler, 1991). There was political indoctrination throughout all levels of education (Zickel, 1991). Classroom environments were formal and regimented, with a reliance on rote learning, lectures, teacher discourse, and textbooks (Steckler, 1991). Discussions between teachers and learners and interactions between learners were limited (Wiggins, 1994). Progress, i.e. grades or marks, was determined by rigorous and comprehensive examinations (Steckler, 1991).

Study of the Russian language was compulsory in elementary and secondary education, although other languages were permitted as a teaching medium. For higher education, science, technology, and the military, Russian was often the exclusive medium of instruction, operation, and research (Gaudiak, 1991). Choosing an education with Russian as the medium of instruction was a means of increasing one's opportunities in education and occupational advancement (Lane, 1992).

Education was compulsory to the 11th year in the mid to late 1980 's, but had been cumpulsory only to the 8th or 10th year from the 1960 's to the early 1980's (Steckler, 1991). Access to higher or specialized education was often easier to obtain for members of CPSU organizations or the children of the elite (Lane, 1992). 
Goals. The primary goal of the Soviet education system was to train and develop soviet citizens (Lane, 1992; MCClare,1991). This included several major goals. The first of these was the inculcation of Soviet values (Lane, 1992). This goal was implemented by imposing ideological conformity in all instruction, from preschool to graduate study, in all subjects (Steckler, 1991). It was also implemented through teaching methods and practices which foster collective thinking and acting, pressure to join CPSU extra-curricular groups, and through the influence and control of the education system by the CPSU and its bureaucracy (Lane, 1992). The second goal was the provision of a free and universal education for all citizens (Zickel, 1991). This provision was achieved through mass literacy, standardized and rigid curriculum and methods (Zickel, 1991; Steckler, 1991). The use of Russian as the national language was another tool for providing a uniform education for all Soviet citizens. Russian was used in all levels of primary education, either with or without another national language, and sometimes exclusively in secondary, higher, and military education, as well in most research, science and technology (Gaudiak, 1991). In practice, however, the promise of a free and universal education often led to a limited number of teachers, many of whom were poorly trained, and a high student to teacher ratio (Steckler, 1991). Because of limited space and resources, overcrowding and shortages were common, especially in rural areas. The massive bureaucracy needed to administer the system led to difficulties in enacting any reforms to the system (Steckler, 1991). 
The third major goal was to train a dedicated and skilled work force (MCClare, 1991) and to use education as a means to shape the economy, research, and society as a whole (Lane, 1992). This involved an emphasis on polytechnical education. Polytechnical education was a means of training students to become good workers (Lane, 1992). This form of education incorporated cognitive, moral, and practical components: developing knowledge of production, respect for and dedication to work, and sound work habits. It was implemented through a combination of formal schooling and practical, sometimes on-the-job, training (Steckler, 1991). Control of the division of labor and the shape of the labor force was also maintained through the education system, by determining the number of educational opportunities in various fields and allocating resources accordingly (Lane, 1992). In practice, allocation of resources was based on short-term, rather than long-term goals and needs. The results of this were mismatches between the labor needs and the labor pool. This led to under-employment, under- or over-qualified workers, and inefficient use of skills, knowledge, and abilities of workers (Lane, 1992).

\section{Classroom Conflicts as an Example of Culture Conflicts}

In the former U.S.S.R., the classroom environment was theoretically quite formal and regimented, oriented towards collectivity. In practice, however, the strict discipline that was reported by Steckler (1991), incorporating oral reprimands, demerits, peer pressure and parental cooperation, often fell short. Unruly classrooms and a lack of respect for authority were common in Soviet 
schools (Ripp, 1984). Cheating was reported to be widespread (Steckler, 1991; Wiggins, 1994). In U.S. Classrooms, Russian-speaking learners are often perceived to be rude or arrogant, unambitious, and, as a group, exclusive and given to cheating (Wiggins, 1994).

But some of these perceptions may be due to cultural differences. The curriculum, method and goals inherent in the Soviet education system are based on developing good work habits, love of work, self-discipline, and collectivity (Steckler, 1991). Wiggins (1994) discusses how these educational values underly the behaviors discussed above.

One example of how cultural styles can cause conflict is the differences in the roles of teachers and learners. Lack of respect for authority, rudeness or arrogance perceived by U.S. teachers could be due to differing views of the status and role of teachers. In the U.S.S.R., teachers were seen as dispensers of knowledge (Wiggins, 1994), setting the parameters and controlling the classroom, while learners were to take in the content primarily through observation. In effect, teachers performed much of the work of learning for the learners. Leamers immersed in the values of the Soviet central government saw themselves as co-equal or in opposition to any authority (Wiggins, 1994). In the U.S., teachers tend to be guides to learning, but learners must do the work of learning, instead of simply absorbing knowledge from the teacher. The conflict between these two styles can lead to negative perceptions on both sides.

The apparent unruliness and 'cheating' could be due to the emphasis on collectivity in Soviet classrooms. In the U.S., the 
emphasis is on individualism and individual work, and collaboration is seen as cheating. These perceptions could also be due to the differences in how the two groups see the process of education. In the U.S.S.R., learning was work. The learning process was straightforward, with little discussion, and little room for questioning on the part of learners (Wiggins, 1994, Steckler, 1991). In the U.S., learning is often informal, with different techniques, discussions, even games or play activities used to help learners in the learning process. It could be that Russian-speaking learners do not see what is occurring in U.S. classrooms as learning, and behave accordingly. Wiggins (1994) reinforces this notion by stating that these learners tend to perceive ESL education as play, rather than work. Another reason could be an antagonistic attitude toward authority, fostered by living under the totalitarian Soviet system (Roberts, 1992).

Similarly, the observation on the part of U.S. teachers that these learners are exclusive may derive from the emphasis on collectivity and group membership and belonging in soviet society and education. It could also be due to either a collective experience of repression or a collective emigre experience (Roberts, 1992). The perceived lack of ambition could come from the lack of opportunities that these learners have experienced in the U.S.S.R., or from opposition to participating in 'the system'. Most of the conflicts between the two groups might very well be based on cultural factors and a lack of understanding of the cultures on the part of both learners and teachers. 


\section{Summary}

While this particular group of learners may have been refugees from the Soviet system, the values and goals of this system still influenced them. The ideological underpinnings of the soviet system dominated all aspects of society and culture, just as the Protestant and capitalist ideologies are inherent in American society and culture. These influences are seen in the experiences, and in the expectations of both Russian-speaking learners from the former U.S.S.R. and teachers in the U.S.. In the area of education, culture affects classroom environment, educational goals, method of teaching and learning, among other things. The differences between the two cultures with respect to education lead to a research expectation that statistically significant differences will be found.

There are many factors that can account for variability among learners, cultural factors are among the most important. Some variables cannot be changed. Others are solely under the control of the learner. Cultural variables can be dealt with by both the learner and the teacher. If cultural factors are not taken into consideration, intercultural conflicts revolving around style and strategy issues can occur. To avoid this, it is necessary for teachers and learners to be aware of differences and to work together to negotiate. Because this is such an important issue, much more research needs to be done in the area of cultural factors affecting learning style and strategy preference and use. 
CHAPTER III

METHOD

INTRODUCTION

This research examines the question of whether or not a significant difference exists with regard to language learning strategy use and preference, between Russian-speaking adult ESL learners and American ESL teachers and prospective teachers. The results of the research could give evidence as to whether or not explicit teaching of language learning strategies is justified in the multi-cultural ESL classroom. The specific hypothesis tested is that there will be some significant differences in the scores of some individual sections, if not overall, between Strategy Inventory for Language Learners (SILL) scores of the two groups aforementioned. if this hypothesis is supported, there will be some justification for the explicit teaching of strategies with emphasis on the different profiles of learners based on language groups.

The hypothesis was tested by administering the SILL to samples of the two populations. Samples were taken from a pool of adult Russian-speaking ESL learners, the target group. Samples were also taken from a pool of American ESL teachers and prospective ESL. teachers, the comparison group. Two versions of the survey, which 
includes the SILL and a demographic questionnaire containing open-ended questions about observed differences in strategy use, were given. One was in Russian, for the target population. The survey given to the comparison group was in English. The results were evaluated, using Analysis of Variance (ANOVA) to determine variance between group and the significance, if any, of the variance. Descriptive statistics were used to analyze demographic information as well as to briefly analyze the SILL scores. Finally, anecdotal evidence from the questionnaires was collected and examined, to note any similarities between the SILL results and the learners' and teachers' own perceptions.

\section{METHODOLOGY}

\section{Variables}

The independent variables in the study are the demographic characteristics of the subjects. The dominant independent variable, the focus of the study, is language group. In this case, language group approximates cultural group (See Chapter I, p.5). The target group is comprised of Russian speakers, while the comparison group is comprised of American English Speakers. Other independent variables, or co-variables, are gender, age and age group, and years of education and education level. The dependent variables being measured in this study are the scores for the SILL, which has six sections and an overall score. 


\section{Subjects}

The target group consists of Russian speakers. The subjects are adults currently studying English, who are former residents of the Soviet Union. The primary educational experience of this group is in the Soviet education system. The primary cultural experience is Soviet as we11. Some of the respondents listed Ukrainian as a first language, along with Russian, but all were exposed primarily to Soviet/Russian education and culture, and had Russian as a dominant language. Only surveys with Russian or Russian and another language listed as native language were used. These subjects were all enrolled in Portland-area adult ESL programs

The comparison group consists of English-speaking Americans, with English as their sole first language. Those who gave another language as an additional first language or used another language at work or at home, i.e. bilinguals, were excluded. This was necessary because of the possibility that bilinguals' primary educational and cultural experiences were not predominantly in the U.S.. The subjests in this group were either students in the Portland State University (PSU) TESOL (Teaching English to Speakers of Other Languages) program, or teachers of respondent Russian-speakers.

\section{Sampling}

Target Population. The sampling method for the target population varied from situation to situation. For all situations, the first step was to contact the heads of local ESL programs by phone. Next, information packets including a letter of introduction, a prospectus of 
the project, and a copy of the survey including the questionnaire and the SILL were mailed to the ESL programs. The next step was to contact individual teachers. At the first school this was accomplished through letters of introduction and follow up letters. Three teachers out of six responded. At the other two schools, the teachers were contacted through the department heads.

The third step was to administer or hand out the surveys. Three methods of distribution and administration were tried, based on the constraints of the individual programs. The most successful was to pull students out of class and to administer the survey during a thirty-minute period. This was possible with only one teacher at the first school. At both of the other schools, where the ESL department heads allowed the researcher to take students from several classes at one time, pullouts were used exclusively. Overall, this resulted in a response rate of seventy-five to one hundred percent. Usable surveys were in the same range. The second method was to hand out the surveys after giving a brief introduction in Russian. This was necessary at the first school, as pull-outs of students were discouraged. This resulted in a response rate of twenty-nine to forty percent. Repeated efforts to remind the students to bring the surveys back to the teachers were made. Usable surveys ranged from fourteen to twenty-seven percent. This method took up two terms and yielded few responses. The third method was a complete failure. This involved mailing introductory letters to teachers in a PSU exchange program in Russia, along with copies of the 
survey, through the director of the program. No responses were ever received. The response rate for groups using the pull-out method was forty-three out of forty-seven, or ninety-one percent. The response rate for groups where the surveys were handed out was ten out of twenty-nine, or thirty-four percent. The overall response rate was forty-seven out of seventy-six, excluding the mailing, or sixty-two percent. (See Table I, below).

TABLE I

RESPONSE RATE FOR TARGET POPULATION

\begin{tabular}{|c|c|c|c|c|c|c|}
\hline Group & Method & \# out & $\#$ In & \# Used & \% In & \% Used \\
\hline A-Class 1 & Pull-out & 3 & 3 & 3 & $100 \%$ & $100 \%$ \\
\hline A-Class 2 & Hand-out & 15 & 6 & 4 & $40 \%$ & $27 \%$ \\
\hline A-Class 3 & Hand-out & 14 & 4 & 2 & $29 \%$ & $14 \%$ \\
\hline A-Total & & 32 & 13 & 9 & $41 \%$ & $28 \%$ \\
\hline B & Pull-out & 16 & 12 & 12 & $75 \%$ & $75 \%$ \\
\hline C-Class 1 & Pul1-out & 18 & 18 & 16 & $100 \%$ & $89 \%$ \\
\hline C-Class 2 & Pull-out & 10 & 10 & 10 & $100 \%$ & $100 \%$ \\
\hline C-Total & & 28 & 28 & 26 & $100 \%$ & $93 \%$ \\
\hline \multirow[t]{2}{*}{ Total } & Pull-out & 47 & 43 & 41 & $91 \%$ & $87 \%$ \\
\hline & Hand-out & 29 & 10 & 6 & $34 \%$ & $21 \%$ \\
\hline Overall & & 76 & 53 & 47 & $70 \%$ & $62 \%$ \\
\hline
\end{tabular}

Comparison Group. The method of sampling and administering the survey to the comparison group was much easier. The professors of the first-term TESOL methods course were contacted. Completion of the SILL is a required assignment for this course. The questionnaire and answer sheet were distributed through the professors, and the surveys were collected one to two weeks later. The response rate for the two classes 
where this was done were twenty-three percent and fifty-five percent, with twenty-three and thirty-two percent usable responses. For one class the researcher was able to administer the survey during class time. This resulted in a response rate of one hundred percent total, and ninety percent usable responses. Overall, the response rate for the comparison group was fifty-nine out of one hundred and six, or fifty-six percent. (See Table II, below).

TABLE II

RESPONSE RATES OF COMPARISON GROUP

\begin{tabular}{|c|c|c|c|c|c|c|}
\hline Group & Method & \# out & \# In & \# Used & $\%$ In & $\%$ Used \\
\hline PSU1 & Hand-out & 39 & 9 & 9 & $23 \%$ & $23 \%$ \\
\hline PSU2 & Pul1-out & 29 & 29 & 26 & $100 \%$ & $90 \%$ \\
\hline PSU3 & Hand-out & 38 & 21 & 12 & $55 \%$ & $32 \%$ \\
\hline \multirow[t]{2}{*}{ Total } & Pul1-out & 29 & 29 & 26 & $100 \%$ & $90 \%$ \\
\hline & Hand-out & 77 & 30 & 21 & $39 \%$ & $27 \%$ \\
\hline Overall & & 106 & 59 & 47 & $56 \%$ & $44 \%$ \\
\hline
\end{tabular}

Combined Groups. The total number of surveys given out was one hundred eighty-two. Of these, one hundred twelve were returned, and ninety-four were used. For both the target population and the comparison group, seventy-six surveys were administered by pull-out, with ninety-five percent returned and eighty-eight percent used. One hundred six surveys were handed out to be returned later. Of these, thirty-eight percent were returned, and twenty-five percent used. Of the ninety-four surveys used in the study, half were from the target population and half from the comparison group. There were forty-seven 
usable surveys from the target group. Usable surveys from the comparison group were randomly eliminated until the two groups were equal in number. (See Table III, below).

TABLE III

RESPONSE RATES FOR TARGET POPULATION AND COMPARISON GROUP

\begin{tabular}{|c|c|c|c|c|c|}
\hline Group & \# out & \# In & \# Used & $\%$ In & $\%$ Used \\
\hline Target Population & 76 & 53 & 47 & $70 \%$ & $62 \%$ \\
\hline Comparison Group & 106 & 59 & 47 & $56 \%$ & $44 \%$ \\
\hline Pull-out & 76 & 72 & 67 & $95 \%$ & $88 \%$ \\
\hline Hand-out & 106 & 40 & 27 & $38 \%$ & $25 \%$ \\
\hline Overall & 182 & 112 & 94 & $62 \%$ & $52 \%$ \\
\hline
\end{tabular}

\section{Composition}

Importance. The study of the composition of these two groups with regard to factors other than language group is necessary. Investigation of factors such as gender, age, and education are important because they show how alike the two groups are. These factors could also affect the results of this research. The more alike the two groups are except for language group, the less likely that other factors could skew the results. Because there were some substantial differences in the composition of the two groups. Because of this, statistical measurements were also taken using each of these factors as the independent variable in order to examine whether or not they could affect the results for the analysis of any differences between the two language groups. 
Lanquage Groups. The target group of Russian speakers was actually composed of two language groups. The majority, who listed their primary language as Russian alone, comprised 64 percent of this group, or 30 of the 47 respondents. The remaining portion, 17 respondents, or 36 percent, gave their primary language as both Ukrainian and Russian. Since the principal consideration was the exposure to the Soviet education system, these two groups were considered to be the target group of Russian-speaking ESL learners (See p.5). The comparison group was homogeneously American English-speaking. (See Table IV, below).

TABLE IV

COMPOSITON OF TARGET AND COMPARISON GROUPS, BY ILANGUAGE

\begin{tabular}{|c|c|c|c|c|c|c|}
\hline \multirow{2}{*}{$\begin{array}{l}\text { Language } \\
\text { Group } \\
\end{array}$} & \multicolumn{2}{|c|}{ Target Group } & \multicolumn{2}{|c|}{ Comparison Group } & \multicolumn{2}{|c|}{ Total } \\
\hline & & $\%$ & & $\%$ & $\mathrm{~N}$ & $\%$ \\
\hline $\begin{array}{l}\text { Russian Only } \\
\text { Ukrainian and }\end{array}$ & 30 & $64 \%$ & 0 & $0 \%$ & 30 & $32 \%$ \\
\hline Russian & 17 & $36 \%$ & 0 & $0 \%$ & 17 & $18 \%$ \\
\hline Russian-speaking & 47 & $100 \%$ & 0 & $0 \%$ & 47 & $50 \%$ \\
\hline American English & 0 & $0 \%$ & 47 & $100 \%$ & 47 & $50 \%$ \\
\hline Total & 47 & $100 \%$ & 47 & $100 \%$ & 94 & $100 \%$ \\
\hline
\end{tabular}

Gender. The distribution of gender was not equal in the two groups, nor was the distribution comparable to that in the general population. In the general world population, the ratio of females to males is estimated to be approximately 51 percent female and 49 percent male (Millett, 1970). For both groups combined, there were 55 women (59 percent) and 39 men ( 41 percent). The ratio of women to men in the 
target group was 47 percent women to 53 percent men. In the comparison group, the proportion was 70 percent women and 30 percent men. (For a more complete compilation, see Table V, below). The disparity of these demographics means that the SIIL scores should be analyzed by applying ANOVA using gender as an independent variable. This analysis is necessary to rule out any effects of gender on the results.

\section{TABLE V}

COMPOSITION OF TARGET AND COMPARISON GROUPS, BY GENDER

\begin{tabular}{|c|c|c|c|c|c|c|}
\hline Group & Women: $\mathrm{N}$ & $\%$ & Men: $\mathrm{N}$ & $\%$ & Total: N & $\%$ \\
\hline $\begin{array}{l}\text { Target Group } \\
\% \text { of Total: }\end{array}$ & 22 & $\begin{array}{l}47 \% \\
23 \%\end{array}$ & 25 & $\begin{array}{l}53 \% \\
27 \%\end{array}$ & 47 & $\begin{array}{l}100 \% \\
50 \%\end{array}$ \\
\hline $\begin{array}{c}\text { Comparison Group } \\
\% \text { of Total: }\end{array}$ & 33 & $\begin{array}{l}70 \% \\
35 \%\end{array}$ & 14 & $\begin{array}{l}30 \% \\
15 \%\end{array}$ & 47 & $\begin{array}{l}100 \% \\
50 \%\end{array}$ \\
\hline Total Population & 55 & $59 \%$ & 39 & $41 \%$ & 94 & $100 \%$ \\
\hline
\end{tabular}

Age. The distribution of individual ages was uneven and unwieldy. For combined groups, the minimum age was 15 years, the maximum 68 years, and the median was 33 years. The mean for the total population was just over 36 years of age. For the target group, the minimum age was 15 and the maximum 67. The mean and median were almost identical, with the mean being nearly 36 and the median age being 36 . For the comparison group, the minimum age was 21 , and the maximum 68 , while the mean and median were just over 35 , and 31 , respectively. (See Table VI, p.42) 
TABLE VI

COMPOSITION OF TARGET AND COMPARISON GROUPS, BY AGE

\begin{tabular}{lrrrr}
\hline Group & Minimum & Maximum & Mean & Median \\
Target Group & 15 & 67 & 35.85 & 36 \\
Comparison Group & 21 & 68 & 35.02 & 31 \\
Total & 15 & 68 & 36.07 & 33 \\
\hline
\end{tabular}

To facilitate use of this variable, ages were put into six groups. The first age group ranges from 15 to 17 years of age; the second, from 18 to 24 ; the third, from 25 to 34 ; the fourth, 35 to 44 ; the fifth group ranged from 45 to 54 ; and the final group from 55 to 68 years of age. The distribution of this grouping was fairly normal, with a slight tendency toward higher ages. This distribution pattern continues in the target group. The comparison group has a slightly different pattern, with two peaks, one in the 25 to 34 age group, and the other in the 45 to 54 age group. (See Table VII, p.43). Because the distributions are somewhat similar it is not expected that age differences would seriously affect the analysis of the SILL scores of the target and comparison groups. Therefore, age was not used as an independent variable in the ANOVA analysis.

Education Education level was divided into three categories. The first of these is secondary education. Secondary education is defined as high school, or nine to twelve years of education in the U.S.. In the former Soviet Union, secondary education is defined as eight to twelve years. This term also includes technical or vocational 
TABLE VI

COMPOSITION OF GROUPS, BY AGE GROUPS

\begin{tabular}{lrrrrrr}
\hline Group & $15-17$ & $\underline{18-25}$ & $\underline{24-34}$ & $\underline{35-44}$ & $\underline{45-54}$ & $\underline{55-68}$ \\
$\begin{array}{l}\text { Target Group } \\
\text { N }\end{array}$ & 2 & 8 & 12 & 17 & 5 & 3 \\
\% of group & $4.3 \%$ & $17.0 \%$ & $25.5 \%$ & $36.2 \%$ & $10.6 \%$ & $6.4 \%$ \\
Comparison Group & & & & & & \\
$\quad$ N & 0 & 8 & 20 & 6 & 12 & 1 \\
\% of group & $0 \%$ & $17.0 \%$ & $42.6 \%$ & $12.8 \%$ & $25.5 \%$ & $2.1 \%$ \\
Total & & & & & & \\
$N$ & 2 & 16 & 32 & 23 & 17 & 4 \\
$\%$ & $2.1 \%$ & $17.0 \%$ & $34.0 \%$ & $24.5 \%$ & $18.1 \%$ & $4.3 \%$ \\
\hline
\end{tabular}

training. The second category is higher education. This includes study at the college, university, or professional level for U.S. respondents, and university or institute study for the target group This term includes the thirteenth through sixteenth years of education. The last category is graduate study. This encompasses any study past the sixteenth year of education, or baccalaureate level in the U.S., and advanced university or institute study in the former Soviet Union. The two groups had distinctly different patterns in education level. 55 percent of the target population had a secondary education. 38 percent had some higher education, and 6 percent had a graduate-level education. The comparison group was comprised of university undergraduate and graduate students, so there were no subjects in this group who had only a secondary education. 70 percent were undergraduate students, and 30 percent were graduate students.

of all respondents, 28 percent had a secondary education, 54 percent had higher education experience, and 18 percent had a 
post-graduate education. (See Table VIII, below). Since the two groups had wel1-defined differences in this area, it was necessary to analyze the scores of the respondents, using education as an independent variable, to discover any evidence that education, not language group, was the defining factor in any differences deemed to be significant.

TABLE VIII

COMPOSITION OF GROUPS, BY EDUCATION

\begin{tabular}{|c|c|c|c|}
\hline Group & Secondary & Higher Education & Graduate Study \\
\hline \multicolumn{4}{|c|}{ Target Group } \\
\hline $\mathrm{N}$ & 26 & 18 & 3 \\
\hline$\%$ & $55 \%$ & $38 \%$ & $6 \%$ \\
\hline \multicolumn{4}{|c|}{ Comparison Group } \\
\hline $\mathrm{N}$ & 0 & 33 & 14 \\
\hline$\%$ & $0 \%$ & $70 \%$ & $30 \%$ \\
\hline \multicolumn{4}{|l|}{ Total } \\
\hline $\mathrm{N}$ & 26 & 51 & 17 \\
\hline$\%$ & $28 \%$ & $54 \%$ & $18 \%$ \\
\hline
\end{tabular}

Summary. The main reason for investigating the composition of the target group and the comparison group is to determine which factors, if any, may account for significant differences found through ANOVA. In this sample, age was ruled out as a factor which would be likely to change the results of the analysis of differences between the two language groups. Gender and education level, however, were shown to have different distributions in the target and comparison groups, and so, could be possible sources of statistical differences. In the analysis using ANOVA, these factors will be tested to see if they could have some bearing on the results. 


\section{Instrument}

The instrument used in this study was a survey. This survey included the Strategy Inventory for Language Iearning (SILL), with permission of the author, Rebecca Oxford, and a questionnaire containing demographic and open-ended questions. The survey was in Russian for the target population respondents, with a shortened version of the SILL and the demographic questionnaire containing questions about language learning. These questions include reasons for studying a language, as well as self-reported proficiency compared to non-native speakers, and to native speakers. The questionnaire also includes an open-ended question about perceived differences in language learning strategies and methodology between the U.S. and former U.S.S.R. educational systems. The survey given to the comparison group includes the SILL for English speakers learning another language, and a questionnaire similar to the questionnaire for the Russian speakers, except that it also includes questions about teaching. The Questionnaire part of the survey was adapted from Rebecca Oxford's background questionnaire for use in conjunction with the SIIL (1991:p282). The Russian-language SILL was provided by Rebecca oxford in 1992, in rough form. It was then back-translated and typed by the researcher. The Russian-language questionnaire was written by the researcher, based on the questionnaire accompanying the SILL in Oxford's Lanquage Learning Strategies: What Every Teacher Should Know (1991). 
The SIIL itself has six sections and an overall score. It consists of a number of sentences which describe specific activities related to learning. Some examples from Oxford (1991: p.283-8) are: "When learning a new word I use rhyming to remember it." "I read for pleasure in the new language." "I ask other people to correct my pronunciation" The respondent reads each sentence then ranks the activity on a five-point scale. This scale ranges from 1 to 5 , with 1 signifying that the statement is "never or almost never true of [the respondent]." to 5 signifying that the statement is "always or almost always true of [the respondent ]." (Oxford, 1991:283).

The six sections of the SILL each deal with a specific set of strategies. The first measures the strategy use or preference for using strategies related to memory and memorization. The second concerns strategies which enable the learner to use several or all mental processes. Oxford categorizes these strategies as cognitive strategies (Oxford, 1991). The third section includes compensation strategies, which help learners compensate when their knowledge of the language is incomplete (Oxford,1991). The fourth measures the use and preference for meta-cognitive strategies, which are involved in organization and appraisal of the learning process (Oxford, 1991). The fifth section determines the use and preference for affective strategies, which facilitates better language learning through awareness and management of emotional factors (Oxford, 1991). The last section deals with social strategies, which involve others in the learning process (Oxford, 1991). 
The scores for the above sections are averaged to assess the particular areas that learners do or do not utilize in their language learning process. The mean scores are evaluated on the same 1 to 5 scale as the individual items. The overall mean score gives an idea of the level of strategy use in general. It is also evaluated in terms of the 1 to 5 scale. Both versions of the SIII used in the study can be found in Appendix A, along with the questionnaire. The versions given to the target population can be found in both the English and Russian versions.

\section{STATISTICAL PROCEDURES}

$\underline{\text { Data }}$

The type of data gathered from the questionnaire includes nominal data (i.e. gender, age, education, etc.) and anecdotal information (i.e. open-ended questions). The data gathered from the SILL was ordinal data, derived from the self-reported frequency of use of the various strategies. The raw scores from the SILL were then averaged to obtain a mean score for each section and for the overall SILL score.

\section{Statistical Procedures}

For nominal data, the main statistical procedures were tabulations. These included frequency counts and percentages of individual categories. Cross-tabulation of more than one category was also done. The results of these procedures gave a picture of the composition of the sample populations. 
For the score data from the SILL, basic statistics such as mean, maximum, minimum, and standard deviation were compiled. The comparison of groups was accomplished by using Analysis of Variance (ANOVA). This is a parametric test which measures the variance within and between groups, and provides the means for determining statistical significance of any differences between groups. The ANOVA was used primarily to look at the two language groups, but the co-variable groups of gender, age, and education level were also compared using ANOVA, to see whether or not these factors were significant, and whether or not they might affect the language group comparisons.

Because of the discrepancy in the number of test items on the two versions of the SIII, mean scores were used in the comparison. The Russian version raw scores were adjusted by multiplying the mean by the number of items on the English version. The ANOVA results using the adjusted data yielded the same result as the mean scores. Another adjustment to the raw scores was the integration of yes/no answers to the five-point scale. Ten out of the forty-seven Russian-speaking respondents gave yes or no answers to the SILL items. To minimize the skewedness of these responses, a "yes" answer was given four points, and a "no" answer was given two. Only one of the surveys adjusted in this way came up in the statistics as a consistent outlier, and the total number of outliers was fairly evenly distributed between the adjusted surveys and the ones originally scored on the five-point scale. 
ANECDOTAL INFORMATION

\section{Overview}

In addition to composition and the statistical evaluation of the SILL scores, anecdotal evidence concerning differences in strategy use and preference was collected. The primary sources were the open-ended questions given to both groups on the survey accompanying the SILL concerning perceived differences. While these sources do not provide "hard" data which can be analyzed statistically, they can provide insight into the mismatches between the two groups and whether or not they are perceived in a negative or positive way. Attitudes and beliefs concerning differences in language learning strategy use and preference can affect or explain resistance to or acceptance of teaching methods on the part of learners, or the ways in which teachers respond to differences.

\section{Target Group}

The questions asked to elicit anecdotal information varied according to the group. For the target group, the question was phrased as follows:

What, in your opinion, are the differences between the study of foreign languages in your country and in America? These differences could be either positive or negative to you, or perhaps you don't find any differences. 
of the participants in the target group, 39 out of 47 , or $83 \%$, chose to answer the open question. Of these, six saw the methods in the former U.S.S.R. as being clearly better than those used in the U.S.. Fourteen thought that the methods in the U.S. were definitely better. The respondents who thought that the methods in their native country were better gave several reasons. Three said that it was better because the instruction was given in Russian. Others said that the explanations were clear and that instruction and learning centered on knowledge of the language. Some respondents' answers were positive towards the methods in the U.S. but included some negative aspects. The inclusion in the same class of learners from diverse educational backgrounds, abilities and ages was a problem for several learners, and the focus on compensation strategies instead of relying on the first language are some examples. Others had difficulty understanding the teacher, or thought that more emphasis on correct pronunciation was needed. Overall, however, it seems that most negative comments about the differences in U.S. methods centered on issues related to the use of the second language, instead of the first language, as the teaching medium in American ESL classrooms.

Positive aspects of American ESL methods appeared to center on the focus on use of the language. The most frequent comment was that the methods were more practical and in-depth. Related comments were that more opportunities for practice were available, and the focus on use made it possible to actually use English much quicker than methods in the U.S.S.R. Another frequent comment was that the standards in the U.S. were much higher than in the U.S.S.R.. Respondents cited 
superficial learning, focus on grammar and reading instead of actually using the language, and little opportunity for contact and practice as examples of the low standards in the former U.S.S.R.. One respondent stated that he had studied German for six years, but could not speak or write in the language. Other examples were low interest in both languages and learning on the part of both learners and teachers, and perceived acceptability of cheating on tests. Several respondents remarked that it was easier to learn English in the U.S., because living in the U.S. made it more necessary to use the language in daily 1ife.

Overall, the respondents favored the methods in their U.S. ESL classes over foreign language classes in the former U.S.S.R.. A number of respondents simply stated that the methods were positive. Some saw little or no differences. Still others responded that they had no experience with foreign language in their native country.

\section{Comparison Group}

The response rate and answers were quite different for the comparison group. One reason is that many had little or no teaching experience. Others that had teaching experience had little or no contact with Russian-speaking learners. The question given to the comparison group was as follows:

What are some of the differences, positive, negative, or neutral, that you have noticed in the language learning styles or strategies of your students? Please note the 
language group and whether you perceive the difference(s) to be positive, negative, or neutral.

of the respondents in this group, 21 out of 47, roughly 45\%, answered the question. Only two of these related directly to Russian-speaking learners. The comments included references to a casual approach to learning and emphasis on social strategy use within the Russianspeaking group. Also mentioned was the observation that learners in this group tended not to read or use English in class.

\section{CONCLUSION}

The goal of this research is to examine whether or not a significant difference is present in the preferences and use of language learning strategies, between Russian-speaking ESL students and American ESL teachers. The independent variable was the language group of the respondents. The co-variables were gender, age and level of education. The dependent variables were the scores on the SILL and its various sections. This was an exploratory study, investigating the differences, if any, that exist between the two groups. As such, no treatment factors were involved.

overall, the procedure for the gathering of information was fairly simple. The subjects in both the target and comparison groups were taken from academic programs. The department heads, teachers, and professors were contacted and permission given to administer the survey. The survey, consisting of a background questionnaire and the 
Strategy Inventory for Language Learning (SILI) was then administered to the subjects, during class time, or by handing out the survey, which the subjects then returned to their respective teacher or professor. These two methods produced very different response rates, with the in-class responses being very high, and the hand-out responses being fairly low. A third method of distribution, by mail, produced no response at al1.

The data received, from both the background questionnaire and the SILL, were analyzed using several statistical procedures. Each procedure was appropriate to the types and roles of the assorted data. Frequency and percents of the independent variables and co-variables, or tabulations, were done. The SIIL scores were tabulated and subjected to Analysis of Variance (ANOVA) tests according to groupings of the independent variables and co-variables. The results of the statistical procedures can be found in the following chapter. 
CHAPTER IV

RESULTS

INTRODUCTION

\section{Significant Differences}

Using the methods described in the previous chapters, results were obtained which provide some answers to the research questions posed at the beginning of this research. The first question to be answered was "Is there a significant difference between the learning strategies of ESL teachers in the U.S. and those of Russian-speaking learners in ESL programs in the U.S.?". The answer to this question lies in the testing of the underlying hypothesis and corresponding null hypothesis. The hypothesis is that there will be significant differences between the target group of Russian-speaking learners and the comparison group of ESL teachers and prospective ESL teachers, with regard to the scores on one or more parts of the SILL. Significant differences in strategy use indicate trends. Trends in strategy use reflect the expectations as well as the practices of the two groups, in relation to each other. The null hypothesis is, conversely, that there will be no significant differences. These hypotheses were tested using ANOVA (Analysis of Variance) to compare the scores of the two groups. 
For any two groups, or even within a single group, there are bound to be differences, i.e. variation. ANOVA tests whether or not the differences between groups exceed the differences within groups. Significance lies in the probability of the resulting margin of difference. That is, what is the likelihood that the differences are due to chance or random factors? The lower the probability, the more significant the difference (Hatch and Lazarton, 1991).

\section{Strategy Profile}

The second research question was "What is the strategy profile of Russian-speaking refugee ESL learners?". A profile is like a map, showing tendencies toward certain characteristics of a group. In this case, the sample size is relatively small, and taken from a specific local area, and a small segment of the Russian-speaking population. Some definite tendencies did show up in this investigatory research. These tendencies could form the basis for loose guidelines for ESL professionals dealing with this population. But, because of the narrow slice that constituted the sample, these results can not be taken as generalizations, or as the basis for forming stereotypes for all Russian-speaking ESL learners.

\section{Validity of Explicit Teaching}

The final question examined in this research was "Does the evidence show that there is a valid reason for explicitly teaching language learning strategies?". It must be mentioned that this is an ambiguous question. If there is any difference at all, that is evidence 
that strategies may be taught to improve the learning process and fill in gaps in knowledge about strategies. The nature of these differences determines the scope of the explicit teaching of strategies that is desirable.

If the differences are stronger among individuals than among groups, then explicit teaching may be advisable in all language instruction for all people. This would have to cover a broad range of strategies and explanations, perhaps too broad for the curriculum of most language teaching. However, if it could be determined that different groups exhibit certain tendencies in strategy use and preference, specific strategies could be used in the classroom to support the strategy profile of the learners. Explicit teaching of strategies that are unfamiliar or avoided could be helpful in improving language learning skills. It could also help learners and teachers develop an understanding of each other's strategy use. Only if there are no clear differences at all would the explicit teaching of strategies be shown to have no validity whatsoever.

\section{RESULTS}

\section{Composition}

The composition of the target and comparison groups and combined groups were discussed in the previous chapter. It is important to look at the composition of the samples to determine whether or not any statistically significant results of the two groups could be accounted for by factors such gender, age, or education. The biggest disparity 
between the two groups was in gender composition. For this reason, all statistically significant results of the comparison between language groups were re-analyzed according to gender. The differences in the age groups were not as great, so it was not necessary to repeat the tests for this factor. A disparity in the educational composition warranted an analysis of the results, using education level as an independent variable.

\section{Basic Statistics}

The preliminary statistical analysis consisted of determining the mean, and calculating the standard deviation of the data. The data consisted of mean scores from the different parts of the SILL and the overall SILL score. The primary independent variable was language group. The covariables were gender group and education group. The basic statistics for language groups, gender groups, and educational groups can be found in Tables IX, X, and XI, on pages 58 and 59.

$\underline{\text { ANOVA }}$

ANOVA is a statistical test for comparing groups. It compares the sum of squares within and between groups and the sum of squares for all scores with the mean of squares for these three groups to determine the amount of variability between groups. This variability is expressed in the F-ratio. This can then be compared to the level at which the probability of the result is .05 or lower or .01 or lower to determine the significance of the results. The lower the probability 
TABLE IX

BASIC STATISTICS, BY LANGUAGE GROUPS

SILL*

Part A Part B Part C Part D Part E Part $F$ overall

Group

Target

$\begin{array}{llllllll}\text { Mean } & 3.213 & 3.376 & 3.681 & 3.981 & 3.100 & 3.940 & 3.556 \\ \text { s.d. } & 0.587 & 0.542 & 0.773 & 0.573 & 0.750 & 0.710 & 0.489\end{array}$

Comparison

$\begin{array}{llllllll}\text { Mean } & 3.024 & 3.597 & 3.691 & 3.412 & 2.866 & 3.605 & 3.399\end{array}$

$\begin{array}{llllllll}\text { s.d. } & 0.489 & 0.480 & 0.490 & 0.547 & 0.549 & 0.496 & 0.369\end{array}$

Total

\begin{tabular}{llllllll} 
Mean & 3.119 & 3.487 & 3.686 & 3.697 & 2.983 & 3.773 & 3.478 \\
\hline
\end{tabular}

Part $A=$ Memory

Part $D=$ Metacognitive

Part $B=$ Cognitive

Part $E=$ Affective

Part $C=$ Compensation

Part $F=$ Social Strategies

Overall= Overall use of strategies

TABLE X

BASIC STATISTICS, BY GENDER

SILL*

Part A Part B Part C Part D Part E Part F overall

Group

Female

$\begin{array}{llllllll}\text { Mean } & 3.175 & 3.550 & 3.758 & 3.672 & 2.934 & 3.688 & 3.482 \\ \text { s.d. } & 0.492 & 0.469 & 0.523 & 0.618 & 0.669 & 0.570 & 0.399\end{array}$

Male

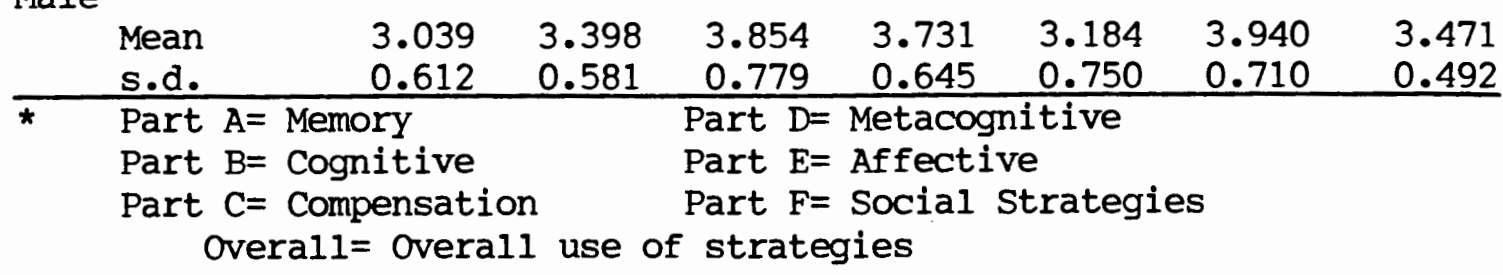


TABLE X

BASIC STATISTICS, BY EDUCATION

SILL*

Part A Part B Part C Part D Part E Part F Overall

Group

Secondary

Mean

s.d.

$$
3.299
$$

$$
3.257
$$

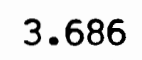

3.991

3.551

3.391

3.562

0.576

$0.520 \quad 0.863$

0.603

0.827

0.737

0.540

Higher Education

$\begin{array}{llllllll}\text { Mean } & 3.015 & 3.528 & 3.636 & 3.641 & 2.851 & 3.814 & 3.432 \\ \text { s.d. } & 0.544 & 0.493 & 0.571 & 0.551 & 0.588 & 0.826 & 0.396\end{array}$

\begin{tabular}{|c|c|c|c|c|c|c|c|c|}
\hline & $\begin{array}{l}\text { Mean } \\
\text { s.d. } \\
\end{array}$ & $\begin{array}{r}3.153 \\
0.449 \\
\end{array}$ & $\begin{array}{l}3.716 \\
0.502 \\
\end{array}$ & $\begin{array}{l}3.838 \\
0.439 \\
\end{array}$ & $\begin{array}{l}3.411 \\
0.726 \\
\end{array}$ & $\begin{array}{l}2.812 \\
0.563 \\
\end{array}$ & $\begin{array}{l}3.801 \\
0.689 \\
\end{array}$ & $\begin{array}{l}3.486 \\
0.386 \\
\end{array}$ \\
\hline * & $\begin{aligned} & \text { Part } A=N \\
& \text { Part } B=C \\
& \text { Part } C=C \\
& \text { Over }\end{aligned}$ & $\begin{array}{l}\text { Memory } \\
\text { Cognitive } \\
\text { Compensati } \\
\text { all= overa }\end{array}$ & & $\begin{array}{l}\text { Part } \mathrm{D}= \\
\text { Part } \mathrm{E}= \\
\text { Part } \mathrm{F}= \\
\text { strate }\end{array}$ & $\begin{array}{l}\text { Metacoo } \\
\text { Affecti } \\
\text { Social } \\
\text { ies }\end{array}$ & $\begin{array}{l}\text { itive } \\
\text { e } \\
\text { trategj }\end{array}$ & & \\
\hline
\end{tabular}

Graduate Study

that the results could have occurred by chance or as a result of random factors, the more significant the results. Hatch and Lazarton (1991) give a complete description of ANOVA, along with a step-by-step explanation of the procedure.

This procedure was chosen because it is more precise than other tests, such as matched t-tests, which only measure the variation between matched groups. Because the goal of this research was to determine if the variation between groups was significantly higher than the variation within the groups, ANOVA was more appropriate. Another reason that ANOVA was more appropriate was the inquiry into whether or not other factors could have caused the variance. Since the divisions by these other factors created uneven groups, the matched t-test was 
deemed inappropriate for the purpose of ruling out these factors as responsible for any significant variation.

\section{Results}

Overview. The degrees of freedom (df) for the three variables considered in this study was 93. The levels of significance for ninety-three degrees of freedom are 3.94 or above for a probability factor of .05 or less, 6.90 or more for a probability factor of .01 or less. During the course of analysis, statistically significant results were obtained for the sections relating to cognitive strategies (Part B), metacognitive strategies (Part D), affective strategies (Part E), and social strategies (Part F). No statistically significant results were obtained for the sections pertaining to memory strategies (Part A), compensation strategies (Part C), or for overall strategy use.

Because the gender distribution is different in the two groups, it is Possible that gender could be a factor in the significance of the results between language groups. Women had higher mean scores on all sections related to direct strategies- memory, cognitive, and compensation strategies. Men had higher scores for the indirect strategies- metacognitive, affective, and social strategies. Women also had slightly higher scores for overall strategy use, although this difference is barely perceptible. The two groups also had large differences in education level. Therefore, analysis of education level to rule out the possibility that these differences skewed the results for the analysis of language groups. A summary of the ANOVA results for all three variables can be found in Figure 3 and Table XII, on page 61. 

Part A Part B Part C Part D Part E Part F overall

Lanquage

Russian

$\star \star$

t)

$\star \star$

English

Gender

Women

Men

$\star \star$

Education

\begin{tabular}{cc}
\hline Secondary & $*$ \\
\hline Higher Ed & $*$ \\
\hline Graduate & Part $\mathrm{D}=$ Metacognitive \\
\hline Part $\mathrm{A}=$ Memory & Part $\mathrm{E}=$ Affective \\
Part $\mathrm{B}=$ Cognitive & Part $\mathrm{F}=$ Social Strategies \\
Part $\mathrm{C}=$ Compensation & Overall $=$ Overall use of strategies
\end{tabular}

Figure 3. Summary of statistically significant results, where $\star=.05$ probability; $\star \star=.01$ probability.

TABLE XII

ANOVA RESULTS

df=93; Probability: $.05=3.94 * \quad .01=6.90 * *$

SILL+ Part A Part B Part C Part D Part E Part F Overall

Ianguage

F-ratio $2.8624 .380 * 0.00624 .223 * * 4.005 * 8.136 * * 3.075$

Gender

$\begin{array}{llllllll}\text { F-ratio } & 1.406 & 1.949 & 1.679 & 0.196 & 2.034 & 4.226 * & 0.016\end{array}$

Education

\begin{tabular}{llllllll} 
F-ratio & 3.455 & $4.687 *$ & 0.819 & $4.915 *$ & $6.646 *$ & 0.059 & 0.967 \\
\hline
\end{tabular}

+ Part $A=$ Memory Part $D=$ Metacognitive

Part $\mathrm{B}=$ Cognitive Part $\mathrm{E}=$ Affective

Part $\mathrm{C}=$ Compensation Part $\mathrm{F}=$ Social Strategies

Overall= Overall use of strategies 
Cognitive Strategies. For the second section of the SILI, concerning cognitive strategies, or the manipulation of language in the learning process, the comparison group had a higher mean score (target group, 3.376; comparison group, 3.597). This difference was shown to be statistically significant $(.05)$. The ANOVA results showed that the English-speaking group was more likely to use cognitive strategies than the Russian-speaking target group ( $f=4.380 ; p=3.94)$. Analysis of gender as a possible factor in the results for this section showed that women scored higher than men (women, 3.550; men, 3.398). However, this result was not statistically significant $(f=1.949 ; p=3.94)$.

In examining possible effects of education level on the use of cognitive strategies, it was shown that the subjects who had a graduate education scored higher than those with college-level or secondary education (graduate, 3.716; higher education, 3.528; secondary, 3.257). This difference was significant $(.05)$ when tested $(f=4.687 ; p=3.94)$. This result appears to be consistent with the results for language groups, as the graduate and higher education groups had higher proportions of comparison group members. All of the secondary education group respondents were from the target group. The comparison group had significantly higher scores. The two education groups with higher proportions of comparison group members than target group members had significantly higher scores. Because of this overlap, there is reason to assume that the education group results are a function of the language group results. 
Metacognitive strategies. The results for the fourth section, dealing with metacognitive strategies, or the organization of the learning process, showed a higher mean score for the target group (target group, 3.981; comparison group, 3.412). This is a prominent area of significant (.01) variation between the two groups ( $f=24.223$; $\mathrm{p}=6.90$ ). This result was by far the greatest gap in strategy use found in this study.

Women scored lower on this section (women, 3.672; men, 3.731). This difference was not very large, and definitely not statistically significant $(f=0.196 ; p=3.94)$.

For this section, the rank of mean scores of education groups was inverse to the level of education; the highest mean score was secondary education, the next, college level, and the third, graduate level (secondary, 3.991; higher ed., 3.641; graduate, 3.411). While there did appear to be a significant variation (.05), it was not nearly as great, or as significant as the results for language groups $(f=4.915 ; p=3.94)$. The significance of the difference between language groups was much greater. In this instance there are two factors which point to the differences between education groups as a function of the differences between language groups. The first indicator is that the rank of the mean scores for this section roughly matches the proportions of the education levels in the target group, which had the higher mean score on this section. The second is that the significance of education is minimal compared to the significance of differences between the target and comparison groups. The lack of contradictory information in this instance leads to a likely conclusion that the education factor is 
instance leads to a likely conclusion that the education factor is mimicking the greater trend.

Affective strategies. The target group also showed a higher mean score for using affective strategies, or strategies relating to emotional factors affecting the language learning process (Target group, 3.100; comparison group, 2.866). This result was found to be significant $(.05)$ by a small margin $(f=4.005 ; p=3.95)$.

Although men scored higher than women (men, 2.934; women, 3.184), ANOVA showed that gender was not a significant factor $(f=2.034$; $\mathrm{p}=3.94)$

With regard to education level, however, the results followed the same pattern as the results for the section relating to cognitive strategies, except that the highest mean scores were for the secondary group, followed by the higher education group, and then the graduate group (secondary, 3.551; higher ed, 2.851; graduate, 2.812). That is, the significance for education level (.05) is greater than that obtained for language groups $(f=6.646 ; p=3.94)$. This could be a result of the high proportion of secondary-educated subjects in the target group. At any rate, no overt contradiction is apparent.

Social strategies. Analysis of the section of the SILL relating to social strategies, or interaction with others in the learning process, showed that the target group scores were also higher than the scores from the comparison group (target group, 3.940; comparison group, 3.605). This result was the second most significant (.01) of the study $(f=8.136 ; p=6.90)$. The implication is that the Russian-speakers were much more likely to use strategies pertaining to the use of and 
preference for strategies connecting to learning in groups or with others.

Men scored higher on this section (men, 3.940, women, 3.688). This difference was a significant (.05). Although this significance was not as great as that for language differences $(f=4.266, p=3.94)$. , the possibility of gender being more important than language on these strategies arises. The gender ratio in the target group was twenty-five males to twenty-two women. The higher ratio of men to women in the target group could be the reason that the target group scored higher on this section. However, the opposite could be true. The higher scores of the men's group could be due to the higher scores of the target group. Since there is a much larger proportion of men in this group, the significance could be a carry-over from the target group scores. This seems more likely, given the difference in the levels of significance.

For this section, only a minimal difference in mean scores was found for education groups (higher ed, 3.814; graduate, 3.801; secondary, 3.391). This result was definitely not significant statistically $(f=0.059 ; p=3.94)$.

Summary. The results of the analysis of the data show several trends. The mean scores on the individual sections were higher for the target group on four sections-memory, metacognitive, affective, and social strategies. The higher scores for the metacognitive and social strategy sections were significant at a .01 level of probability, with a very high margin for metacognitive strategies. The higher scores for the affective strategy section were significant at the .05 level. The 
not significant. The comparison group had higher mean scores for two sections- cognitive and compensation strategies. The difference in mean scores for cognitive strategies was significant at the .05 level. The scores for the compensation strategies were not significant.

\section{CONCLUSION}

Significant differences were found with respect to the scores for several portions of the SILI. This outcome leads to a rejection of the null hypothesis stated earlier. Four areas showed significant differences. The significance of the higher mean scores for the target group on the metacognitive and affective strategies portions, and for the comparison group on the cognitive strategies portions of the SILL remains solid, even after other factors are taken into consideration.

These results seem to indicate that the explicit teaching of language learning strategies could be useful for Russian-speaking ESL learners in the area of cognitive strategies. The main importance of these results is that significant differences can occur between language groups. The implication of this is that the issue of explicit teaching of language learning strategies should be explored further, with regard to specific language groups encountered in ESL teaching. ESL teachers or future ESL teachers should receive training in identification and use of strategies in all areas to make them effective in cases where explicit teaching is advisable. Further discussion of these issues can be found in the following chapter. 
CHAPTER V

DISCUSSION

INTRODUCTION

The research hypothesis for this study was that statistically significant differences would be found with respect to the language learning strategies of Russian-speaking learners and ESL teachers in the U.S.. The preference for and use of language learning strategies was tested using the Strategy Inventory for Language Learning (SIII) developed by Rebecca Oxford (1991). Statistically significant results were obtained through ANOVA in four sections, regarding cognitive strategies, metacognitive strategies, affective strategies, and social strategies. In addition to the statistical evidence, anecdotal evidence was collected that showed that differences were observed by the learners and by teachers who came into contact with them. This evidence also showed that differing expectations caused stress in the classroom. In this chapter, the research questions posed at the beginning of the study will be examined in the light of these results. The limitations of the study will be considered. Implications for the teaching of ESL or other fields of work with persons of other cultures, and for further research in this area will also be discussed. 


\section{DISCUSSION OF SIGNIFICANT FINDINGS}

\section{Cognitive Strategies}

Cognitive strategies are direct strategies which involve using and integrating several mental processes and developing independent thinking and analytical skills in the language learning process. The result for this section was that the comparison group of teachers and potential teachers scored significantly higher than the target group of learners.

Looking back at the discussion of differences between Soviet and American educational systems, it is not surprising that cognitive strategies were not preferred or used as much by the learners as the teacher group. Soviet methods were focused on the transmission of knowledge from teacher to learner. Cognitive strategies involving thinking about, processing and using the second language were not priorities in elementary or secondary level language learning. Knowledge about the language was more important than active communication. Language teaching and learning appears to have been more academic than practical, perhaps because there were limited opportunities for practical use of foreign languages. It should be noted, however, that immersion programs were used in some specialized secondary schools and in some higher education programs and institutes. But for most Soviets, the experience of language learning was not geared towards actual use. A second factor which may account 
for this result is the use of the first language as the medium of instruction for foreign languages.

Both of these differences between the two systems were remarked upon by the learners in this study. Specifically, mention was made of the emphasis on use in U.S. ESL classes, and the focus in the soviet system on learning about a language instead of being able to communicate in it. Some learners said that they felt that U.S. teachers were not clear enough in their instruction about the language, or that they were not actually teaching, but making the learners do the work meant for teachers. Numerous learners complained that all the instruction was in English instead of Russian. These responses indicate an uncomfortableness with cognitive strategies, many of which are based on thinking about and using the additional language in as many ways as possible.

The importance of the difference in use of cognitive strategies is that it highlights cultural differences in the way thqt language learning is perceived. In Soviet culture, it is seen as an academic subject and a transfer of knowledge. In the U.S., language learning is seen as a dynamic process leading to ability to communicate and understand the language. This mismatch and the resulting discomfort in this area reported by learners show that explicit instruction and discussion of learning as a process are advisable. Explanation and cultivation of specific cognitive strategies, as well as negotiation and opportunities for feedback on the part of learners, may make the language learning process more meaningful and therefore more effective for this group of learners. 


\section{Metacognitive Strategies}

Metacognitive strategies are indirect language learning strategies which involve the organization and monitoring of the learning process. The difference between the two groups was the most well-defined result of the study. The target group had a significantly higher score on this section by a large margin.

Again, the differences between the two cultures, shown by differences in education, lead to an explanation of the mismatch of strategy use in this area. Values in the Soviet culture emphasize self-discipline and developing good work habits. Educational methods incorporate these values. The teacher imparts knowledge to the learners. For the most part, it is up to the learners to manage their learning beyond that point. Grading is based on comprehensive exams, and the learner has the responsibility to prepare and to monitor progress. In the U.S., the teacher is a guide, and leads learners through the steps involved in the procedure of learning, through practice, breaking down learning tasks, and incremental grading based on homework, attendance, and other factors, as well as exams. The educational process is managed and monitored by the system, not by the individual.

Teachers surveyed in the study noted that their Russian-speaking learners were casual about learning in the classroom with U.S. methods. Wiggins (1994) reported that learners in this group tended to see U.S. methods as encouraging play, rather than work, and appeared to teachers not to take classes seriously. The learners in this study 
often reported that learning in U.S. classrooms was more practical and in-depth, showing learners how to improve their skills and use the language. Some did mention, like those in Wiggins' study, that learning was not as serious as in their native country. This attitude was also found in the researcher's teaching experience, where learners sometimes were resistant to the in-class exercises and practice.

The differences in this case are important because they show that variation does not necessarily indicate a deficit on the part of learners. In this instance, the learners showed a strength in this area. They had a strong awareness of metacognitive strategies and were more likely to use them. In the classroom, this factor can be utilized to help learners from cultures other than the two involved in this study to develop their metacognitive strategy use. Explicit teaching of strategies can foster more awareness of strategy use. Discussion and encouragement could be helpful in negotiation of classroom strategy use. In addition, an integrated teaching approach building on the existing strengths, such as organization of learning tasks, setting goals, and self-monitoring, to explore and encourage the use of other strategies may be helpful to both learners and teachers. For

a more detailed explanation of the teaching of strategies, see oxford (1990)

\section{Affective Strategies}

Affective strategies are indirect strategies that help the learner to be aware of emotional factors, such as attitudes, stress, and level of confidence. These strategies also enable the learner to 
manage these factors more effectively. Members of the target group had a significantly higher score for these strategies than members of the comparison group.

As with metacognitive strategies, affective strategies are compatible with the Soviet values of self-discipline and self-control and with the emigre experience. They also fit with the values of collectivity and being a good citizen. If a person is aware of their affective state and is able to manage that state, then they are more likely to fit into a collective culture. The educational goal of integrating all aspects of life, work and education also fosters effective use of this set of strategies. The demands of living under a repressive system and being an immigrant in a vastly different culture might also tend to foster the same traits. On the other hand, the American values of individuality and innovation may tend to make Americans less aware of how their affective state affects the learning process. While these strategies were not specifically mentioned in the responses to the open question on the survey, some discomfort and some excitement at engaging new ways of learning are evident.

Affective strategies are important to the language learning process because discomfort, anxiety, and self-confidence can help or hinder the learner. Even though these learners had a strong preference for using these strategies, they may not be aware of the ways in which they are helpful. An awareness of strategies may make their use more effective. Discussion of the ways that emotional factors affect learning and individuals is in itself one of the affective strategies. There is also the question of transferability. Learners may know how 
to implement strategies in their native environment, but may be at a loss in the very different classroom environment of the U.S.. Emotional factors are also more overwhelming, as these learners are not just experiencing different educational practices, but changes in every aspect of their lives. Explicit discussion and implementation of affective strategies may, therefore, be helpful not only in adapting to a new classroom environment, but in other areas of change as well. Awareness of intercultural differences and options can lead to better understanding and easier adaptation (See Albert, 1983).

\section{$\underline{\text { Social Strategies }}$}

Social strategies are concerned with engaging other people in the learning process. The SILL scores of the target group showed a preference for this type of learning strategy. These strategies are important to the language learning process because of opportunities for practice, cooperation, correction, clarification, problem-solving, and help.

Given the previously mentioned value of collectivity and the values of collaboration, cooperation and group membership mentioned in the review of the literature, it is not inconceivable that learners from the former Soviet Union should have a preference for using social strategies. In the U.S., with a cultural emphasis on individualism, these learners often find conflict in ESL classrooms. What may appear to be a social strategy to the learner seems to the U.S. ESL teacher to be cheating. Americans have a strong tendency against collaboration in the classroom, except for activities designated as group projects. 
The aspect of reliance on the group on the part of learners includes use of Russian in the classroom instead of English and exclusion of learners from other groups. Sometimes unruliness or ignoring teachers in the classroom might be due to notions of in-group and out-group, with non-Russian-speakers constituting the out-group (Wiggins, 1994).

All of the above activities have been noted in teacher survey responses. Examples can also be found in Wiggins' 1994 study, and in the researcher's experience in the classroom. The learners' responses to the survey question showed strong group ties and a desire for exclusion of outsiders from ESL classrooms, i.e. segregation of language groups and leamers with differing abilities. Several learners also said that cheating was widespread. Others said that they were not able to work together as much as they liked, or to use their first language to talk with each other and help each other out.

The results in this area are very important, because it seems that most of the negative perceptions of both learners and teachers seem rooted in the conflicts raised by differing ideas of group and the individual. It also appears that this group of learners has difficulty transferring the social strategies from a Russian language environment to an English language environment. Explicit teaching and discussion could increase understanding, help learners transfer the strategies to the U.S. ESL classroom, and lessen stress and anxiety caused by cultural misunderstandings. It is definitely an issue that teachers need to know about, and that needs to be discussed in the classroom. 
Summary

The first of the research questions posed was "Is there a significant difference between the learning strategies of ESL teachers in the U.S. and those of Russian-Speaking learners in ESL programs in the U.S.?". In this case, the answer to this question is yes. It has been shown that significant differences were found for four sections of the SILI. These differences reflect differences in expectations and classroom behaviors of both teachers and learners.

The second research question was "What is the strategy profile of Russian-speaking refugees ESL learners. The profile in this study showed a strong preference for metacognitive, affective, and social strategies. It also showed that cognitive strategies were not preferred or used often. The anecdotal evidence from both the target group and the control group reflect the results of the SILL.

The last research question explored in this study was "Does the available evidence show that there is a valid reason for explicitly teaching language learning strategies?". The answer to this question, in reference to the data from this study, is also yes. The differences between the two groups, as seen by individual responses, SILL results, and the literature, can lead to conflict between the two groups in the classroom. Many of the specific conflicts can be traced to cultural differences which form the bases for the trends in strategy use and preferences measured by the SILL. Explicit teaching about the nature of language learning strategies and their use can expand awareness about one's own preferences and patterns, as well as the preferences and patterns of others. It can also, through discussion and 
explanation, lay the groundwork for negotiation processes and conflict resolution in the classroom.

LIMITATIONS OF THE STUDY

\section{Data Collection}

Limitations of this study included procedures in gathering data, procedures in analyzing data, and limited scope. With respect to gathering data, the main considerations were time, method, and cooperation. The first time delays were due to obtaining translations of the SILI and the accompanying survey. The Russian version of the SIIL was provided by Rebecca Oxford, in the form of a handwritten draft. This draft had to be typed by the researcher, who had very little experience in typing in Russian. This final draft was checked and re-checked by a professor who teaches at Portland State University. The questionnaire presented problems. The first translator produced a highly inaccurate and useless version. The work had to be completely redone, at the researcher's expense, causing further delay in the administration of the surveys.

The collection process took much longer than expected because of the methods available in administering the survey and because of resulting response rates. The first method tried was to hand out the surveys, then to collect them after they were returned by the respondents. The problem with this method was that most respondents did not return them. This problem was discussed in Chapter III. Improved access to learners was finally granted at the second and 
third schools, after three terms had been spent trying to collect data at the first school. Improved access meant that the researcher was allowed to administer the survey during class time. Another reason that the collection of data took so long was that most data from the comparison group was collected during the second part of the TESOL methods course at Portland State University, which is only taught two out of three terms during the school year.

Some of the limitations due to cooperation concerned problems with procedure, while others were due to cultural factors. Some of the respondents collaborated in their responses to the survey. Since overt examples of copying answers were few, the researcher was not overly concerned. From the discussion overheard by the researcher, most of the collaboration was geared towards trying to figure out what was meant by the items relating to unfamiliar strategies and did not affect results. Another cooperation factor was that some respondents simply did not understand the ranking system of the SILL, and instead wrote 'yes' or 'no' (in Russian, of course) as responses. This was mitigated by assigning the values of 4 for a 'yes' answer and 2 for a 'no' answer. These values are not extreme and should not have affected the statistical results in a significant way.

\section{Data Analysis}

Limitations due to procedures in data analysis included both translation and applications of statistical methods. All translation of responses was done by the researcher. Since the responses were handwritten, it was sometimes difficult to figure out the Russian. 
However, the translations were checked and double-checked, and the researcher believes that the translations for the responses used in the study were accurate.

The statistical analysis of the data was more problematic, as the researcher had little background in statistical procedures. A tutor was consulted to enable the researcher to be able to understand the procedures and to be able to work them out by hand before the computer analysis was done. If there had been time, and the researcher had had more experience and expertise, more statistical procedures might have been included in the analysis.

\section{Scope}

The scope of this study was a major Iimitation. Respondents were residents of the Portland-Vancouver metropolitan area who were attending one of four schools. This meant that the group in the study may be less representative of the target and comparison groups than subjects in a study that had a broader geographical scope. The number of subjects was also a limitation. If the sample had been larger, then the results might have been more representative. With the size of the study and the narrow range of background of respondents in mind, the results of this study are still helpful, especially to those dealing with this specific group of learners.

The scope of the survey was also a limitation. In retrospect, it is probable that the researcher would have included more open-ended questions on strategies, expectations, and perceptions on the questionnaire accompanying the SILL. These questions could have 
provided more backup for the SILL results, as well as aiding in interpretation of the results in the light of cultural differences.

IMPLICATIONS FOR ESI

Cultural patterns of variations are important in teaching and learning language because they can lead to conflict, ineffective implementation of teaching methods, and other problems for both teachers and learners, inside and outside of the classroom. Resolution and prevention of these problems can be accomplished. First, there is a need for awareness and anticipation of diversity. Teachers cannot expect that their ESL learners will have the same educational background that they have. This background includes amount of education, content, method, and goals of education. It is not advisable to assume that an ESL learner will necessarily understand implicit instructions and procedures such as taking an exam, writing a composition, or even taking a survey. The fact that there will be differences between teachers and learners and among learners with different cultural backgrounds needs to be taken as a given.

Assessment of cultural profiles of style and strategy preferences and use comes next. A cultural profile of language learning strategies will help ESI teachers to organize and create more productive curricula, materials, and tests, as well as provide ways to teach more effective strategy use in the classroom. Constructing such a profile can be done using the SILL and/or other measurements of style and strategy preferences. The instrument should be given in the first 
language, if possible, of the learners. An investigation of learners' profiles should also include verbal or written responses to questions about preferences, experiences, and expectations. Since most ESI programs have speakers of most of their learners' known languages to process and assist in academic evaluations, these persons could also assist in administering the profiles. Ongoing assessment can be done in the classroom, informally, as part of the process of reconciliation and negotiation.

Finally, differences which are not necessarily problematic can be negotiated so that both teachers and learners feel comfortable and the learning process can be more effective. Differences which could cause problems need to be reconciled. Both of these can be done through explicitly teaching and discussing variation, negotiation, adjusting curriculum, and creation of a classroom culture. Explaining assignment procedures and testing methods in a step-by-step process, and perhaps having run-throughs could also be helpful. The expectation of differences, methods of assessing differences, and methods of dealing effectively with differences should be covered in ESL teacher training programs. Since the complexity of learning tasks generally increases with proficiency in the target language, the second language could be used for discussion, negotiation, and instruction of strategies at an appropriate level.

One example of dealing with difference with the group of learners sampled in this study is to explore possible ways of coping with the differences in use and preferences of social strategies. Negotiation on this area can help if the two groups, as well as other groups in 
the classroom, try to work out what is really important. Discussion of differences in expectations and processes can lead to negotiations. Perhaps American teachers can ease up on collaboration on assignments, if it is done in English and is not exclusive to Russian speakers, and independent work is done on tests and exams. In one class that the researcher taught, this was done, and other culture groups were helped by collaboration and help from the Russian speakers in the class. A drawback, however, was that Russian letters and spelling errors began appearing on papers and quizzes from learners in other language groups.

Awareness of cultural differences is also important to professionals in other fields, who must deal with people from different backgrounds. Many of the methods of reconciliation and negotiation discussed with respect to ESL professionals can be adapted to other contexts as well. Anyone working with persons from different cultures needs to be aware of the problems of intercultural communication, and ways of communicating effectively across cultures.

\section{IMPLICATIONS FOR RESEARCH}

There is a definite need for more research on this specific issue. Research could be done in the area of strategy and style assimilation over time. Experimental research on possibilities and effectiveness of various ways of reconciliation would certainly be of use for teachers in designing curricula and planning for classroom management. Perhaps one of the most needed types of research on this 
issue is developing profiles of different groups. While not all members of a cultural group would be identical in their preferred styles and strategies, trends that are significant, and common traits should be noted. This could be accomplished through mass surveys across cultures, which could be analyzed to find correlation between learning orientations and culture. More detailed studies could be done on specific groups, using ethnography, research on educational systems in other cultures, surveys, and observations. An example of such research is Frechette's (1987) investigation of Saudi culture. Testing issues relating to this topic are also a possible area for further research. of course, there is always room for replication of previous studies, to check the validity and reliability of research methods, and to expand existing research, into other cultures or educational settings, for example. 
REFERENCES

1) Albert, Rosita. (1983). "The intercultural sensitizer or culture assimilator: A cognitive approach." in $D$. Landis and R. Brislin (eds.). Handbook of intercultural training volume II: Issues in training methodology. (pp. 186-217). New York: Pergamon Press.

2) Bentahila, Abdelâli, and Davies, Eirlys. (1989). "Culture and language use: A problem for foreign language teaching." International Research in Applied Linquistics, v.27 no.2: 99-112.

3) Brown, Gillian. (1989). "Making sense: The interaction of linguistic expression and contextual information." Applied Linquistics. v.10 no.1: 97-108.

4) Brown, H. Douglas. (1987). Principles of lanquage learning and teaching. Englewood Cliffs, New Jersey: Prentice Hall Regents.

5) Byrd, Patricia. (1986). "Barriers to cross-cultural communication in English-as-a-second-language programs in the United States." in Patricia Byrd (ed.). Teaching English across cultures in the university ESL program. (pp. v-x) Washington, DC: National Association for Foreign Student Affairs.

6) Cameron, Judy, and Epling, Frank. (1989). "Successful problem solving as a function of interaction style for non-native students of English." Applied Linguistics. v.10 no.4: 392-406.

7) Cargill, Carol. (1987). "Cultural bias in testing ESL." in Carol Cargill. (ed.). A TESOL professional anthology: Culture. (pp. 1-7). Lincolnwood, Illinois: Voluntad Publishers.

8) Carroll, J.B.. (1965). "The prediction of success in foreign language training." in R. Glaser (ed.). Training, research, and education. New York: Wiley.

9) Coady, James. (1979). "A psycholinguistic model of the ESL reader". in Reading in a second lanquage. Rowley, MA: Newbury House.

10) Evans, Linda. (1987). "The challenge of a multicultural elementary ESL class: Insights and suggestions." in Linda Cargill (ed.). A TESOL professional antholocy: Culture. (pp. 9-19). Lincolnwood, Illinois: Voluntad Publishers. 
11) Faerch, Claus, and Kasper, Gabriele. (1983). Strategies in interlanguage communication. New York: Longman.

12) Fitch, Kristine. (1987). "Cultural conflicts in the classroom: Major issues and strategies for coping." in Patricia Byrd (ed.). Teaching across cultures in the university ESL program. (pp. 51-62). Washington, DC: National Association for Foreign Student Affairs.

13) Frechette, Ernest. (1987). "Some aspects of Saudi culture." in Carol Cargill (ed.). A TESOL professional anthology: Culture. (pp. 61-71). Lincolnwood, Illinois: Voluntad Publishers.

14) Furey, Patricia. (1986). "A framework for cross-cultural analysis of teaching methods. "in Patricia Byrd (ed.). Teaching English across cultures in the university ESL program. (pp. 15-38). Washington, DC: National Association for Foreign Student Affairs.

15) Gaudiak, Thor B.. (1991). "Nationalities and Religions." in Raymond E. Zickel (ed.). The Soviet Union: A country study. Washington, D.C: Federal Research Division, Library of Congress.

16) Gurney, David. (1987). "Total immersion of welcome outsiders: Cross-cultural encounters." in Carol Cargill (ed.). A TESOL professional anthology: Culture. (pp. 113-120). Lincolnwood, Illinois: Voluntad Publishers.

17) Hatch, Evelyn, and Lazaraton, Anne. (1991). The research manual: Design and statistics for applied linguistics. New York: Newbury House Publishers.

18) Kunz, Brian. (1991). "Report of visit to Moscow State University." ERIC Document no. 342587.

19) Lane, David. (1992) - Soviet society under perestroika. New York: Routledge.

20) Lenin, Vladimir Ilyich. (1932). State and revolution. New York: International Publishers.

21) Lennon, Paul. (1990). "The advanced learner at large in the L2 community: Development in spoken performance." International Research in Applied Linquistics. v.28 no.4: 309-324.

22) Levinsky, Alex, and Rubinstein, Sura. (1994). "Political and religious refugees from around the world find oregon fertile ground for relocation." The Oregonian. June 26, 1994: L-4. 
23) Little, Greta, and Sanders, Sara. (1989). "Classroom community: A prerequisite for communication." Foreign Lanquage Annals. v.22 no.3: 277-281.

24) Lono, Luz Paredes. (1987). "Cultural aspects in the development of reading comprehension skills." in Carol Cargill (ed.). A TESOL professional anthology: Culture. (pp. 79-92). Lincolnwood, Illinois: Voluntad Publishers.

25) Maurice, Keith. (1986). "Cultural styles of thinking and speaking in the classroom." in Patricia Byrd (ed.). Teaching across cultures in the university ESL Program. (pp. 39-50). Washington, DC: National Association for Foreign Student Affairs.

26) MCClare, Daniel E.. (1991). "Physical environment and population." in Raymond E. Zickel (ed.). Soviet Union: A country study. Washington, D.C.: Federal Research Division, Library of Congress.

27) Millett, Kate. (1970). Sexual politics. New York: Doubleday•

28) Naiman, N., Frohlich, M., Todesco, A., and Stern, H.H.. (1978). The good lanquage learner. Ontario, Canada: Ontario Institute for Studies in Education.

29) Nayar, P.B.. (1986). "Acculturation or enculturation: Foreign students in the United States." in Patricia Byrd (ed.). Teaching English across cultures in the university ESL program. (pp. 1-14). Washington, DC: National Association for Foreign Student Affairs.

30) Nyirady, Kenneth E.. (1991). "Social structure." in Raymond E. Zickel (ed.). Soviet Union: A country study. Washington, D.C.: Federal Research Division, Library of Congress.

31) O'Malley, J.M., Chamot, A.U., Stewner-Manzares, G., Kupper, L., and Russo, R.P.. (1985). "Learning strategies used by beginning and intermediate ESL students." Lanquage Learning. 35: 21-46.

32) Oxford, Rebecca. (1990). Language learning strategies:What every teacher should know. Boston: Heinle \& Heinle.

33) Oxford, R., Lavine, R., and Crookall, D.. (1989). "Language learning strategies, the communicative approach, and their classroom implications." Foreign Lanquage Annals. v. 22 no.1: 29-39. 
34) Peck, Sabrina. (1991). "Recognizing and meeting the needs of ESL students." in Marianne Celce-Murcia (ed.). Teaching English as a second or foreign lanquage. (pp. 363-371). Boston: Heinle \& Heinle.

35) Richmond, Katherine. (1987). "Cross-cultural coping: Suggestions for Anglo teachers of ESL to Native Americans." in Carol Cargill (ed.). A TESOL professional anthology: Culture. (pp. 21-31). Iincolnwood, Illinois: Voluntad Publishers.

36) Ripp, Victor. (1984). Moscow to main street: Among the Russian emigrés. Boston: Little, Brown, and Company.

37) Roberts, Amy. (1992). Internal-external locus of control and the life experiences of Soviet Pentecostal refugees in Portland, Oregon. Portland: Portland State University. (Thesis).

38) Roberts, Amy, and Locke, Steven. (1991). "Resettlement and acculturation of Soviet Pentecostal refugees in Oregon." ORTESOL Journal. v.12:33-49.

39) Rost, Michael, and Ross, Steven. (1991). "Leamer use of strategies in interaction: Typology and teachability." Language Learning. v.41 no.2: 235-273.

40) Saville-Troike, Muriel. (1976). Foundations for teaching English as a second lanquage. Englewood Cliffs, NJ : Prentice-Hall.

41) Scarcella, Robin. (1990). Teaching language minority students in the multicultural classroom. Englewood Cliffs, New Jersey: Prentice Hall Regents.

42) Si-Qing, Chen. (1990). "A study of communicative strategies in inter-language production by Chinese EFL learners." Lanquage Learning. v.40 no.2: 155-187.

43) Skallerup, Thomas. (1991). "Historical setting: 1917 to 1982." in Raymond E. Zickel (ed.). Soviet Union: A country study. Washington, D.C.: Federal Research Division, Library of Congress.

44) Skehan, Peter. (1989). Individual differences in second lanquage learners. New York: Routledge, Chapman, Hall.

45) Skehan, Peter. (1991). "Individual differences in second language learning." Studies in Second Lanquage Acquisition. 13:275-298. 
46) Steckler, Irene M.. (1991). "Education, health and welfare." in Raymond E. Zickel (ed.). Soviet Union: A country study. Washington, D.C.: Federal Research Division, Library of Congress.

47) Tarone, Elaine. (1983). "Some thoughts on the notion of 'communication strategies'." in Claus Faerch and Gabriel Kasper (eds.). Strategies in interlanquage communication. (pp. 61-74) New York: Longman.

48) Wardhaugh, Ronald. (1969). Reading: A linquistic perspective. New York: Harcourt, Brace, and World.

49) Wiggins, Patricia. (1994). Soviet evangelicals in adult ESL classes: A case study. Portland, OR: Portland State University. Thesis MS.

50) Wright, Tony ( 1987). Roles of teachers and learners. New York: Oxford University Press.

51) Zickel, Raymond E. (ed.). (1991). Soviet Union: A country study. Washington, D.C.: Federal Research Division, Library of Congress. 
APPENDIX A

SURVEY : ENGLISH VERSION 
Background Questionnatre

1. Code:

2. Date

3. Age

4. Sex

5. Level of education: (Circle highest year completed) College 1234 Graduate School $1234+$

6. Mother Tongue

7. Language(s) you speak at home:

8. Language you are now learning or have most recently learned:

9. How long have you been studying the language 1 isted in 18 ?

10. Have you studied other languages bestdes the language listed in 18 ? (Circle one) Yes No

11. How do you rate your overall proficlency in the language 11 sted in 18 , as compared to the proftctency of other students in your class? (ctrcle one) Excellent Good Falr Poor

12. How do you rate your overall proftctency in the language 11 sted in 18, as compared to the proffctency of native speakers of the language? (circie one) Excellent Good Fatr Poor

13. How important is it for you to become profictent in the language ilsted in 18? (Circle One) Very Important Important Not so Important

14. Why do you want to learn the language 11sted in 18 ? (Check all that apply)

a.

Interested in the language'

b. Interested in the culture

c._- Have frtends who speak the

d. - Requited course for degree

language

e. Need it for career

f._ Need it for travel

9._ Other (List):

15. Do you enjoy language learning? (Ctrcle one) Yes No

16. Have you taught English as a Second Language (ESL), English as a Forelgn Language (EFL), or any other form of Teaching Engifsh to Speakers of Other Languages (TESOL)? (CIrcle all that apply) ESL EFL Other

17. Have you taught students from the following language groups? (Check all that apply)

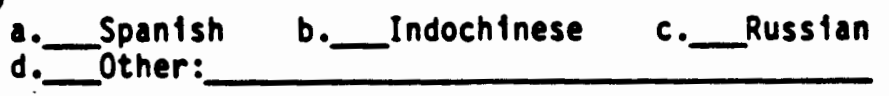

18. Which levels have you taught? (Check all that apply)

a._ K-6 b._ 7-12 c._College-Level d.__ Adult Education

19. What are some of the differences, positive, negative or neutral, that you have noticed in the learning styles or strategtes of your students? Please note the language group and whether you perceive the difference(s) to be positive, negative or neutral. 


\section{Strategy Inventory for Language Learning (SILL) Version for English Speakers Learning a New Language}

Strateg bvenuory for Lequage Leming (SRL)

Verion 5.1

(c) Rosting is

D.a.t.

The STRATEOY DVENTORY FOR LANGUACE LEARNMO (NII) is deal ond to the

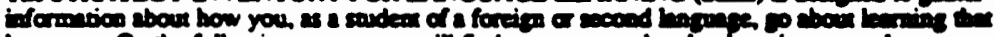

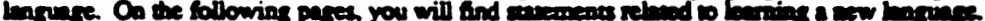

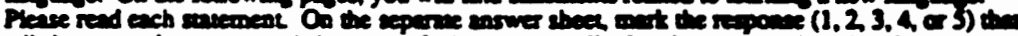

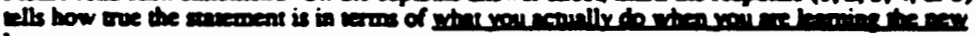
innine.

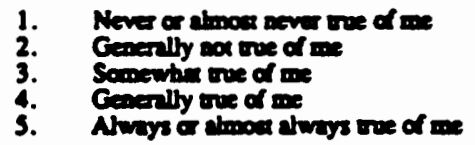

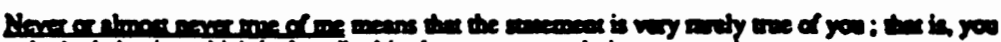

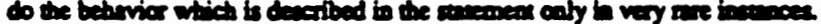

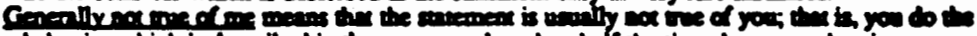

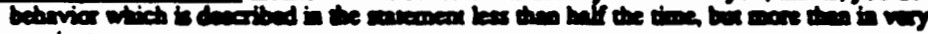

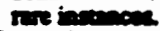

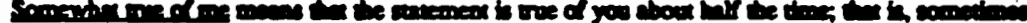

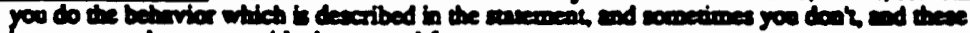

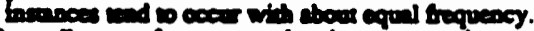

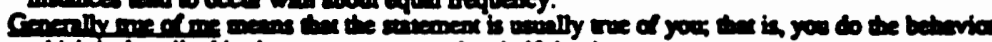
Which is deccilbed to the ronconen more then Mif the time.

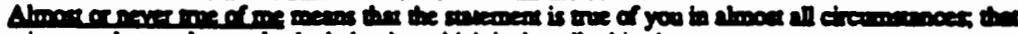

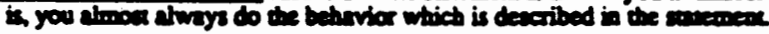

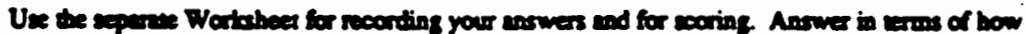

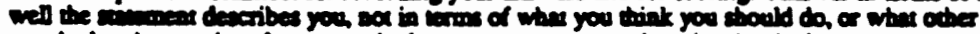

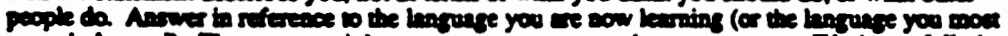

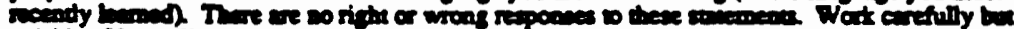

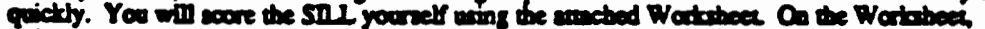

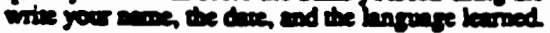

(Version 5.1, • R. L. Oxford, 1909)

[From: Oxford, Rebecca. (1990). Language Learning Strategies: What Every Teacher Should Know. New York: Newbury House. (pp.283-288). 


\title{
STRATEGY WVENTOAY FOR LANGUAGE LEARNING
}

\section{EXAMPLE}

\author{
1. Never or alooca never bue of ane \\ 2. Ceserally nox trie of me \\ 3. Socrewtint me of me \\ 4. Coverally are of on

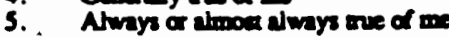

Read the inem, and choose a response (I through 5 as above), and write in in the apace after the item.

I scrively seck out opporsunities of ull with neive speakers of the new lingunge

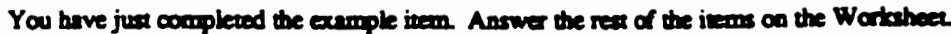

\section{Strategy Inveatory for Lapunge Laraiag}

$$
\text { Veromen } 5.1
$$

(c) R. Oafort ises

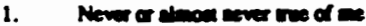

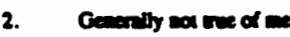
3. - Somontre or of
4. Conenly ne of 2

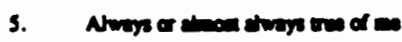

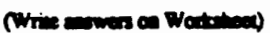

\section{Bas}

When bering a now word ...

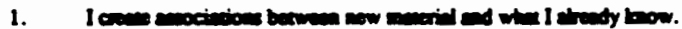

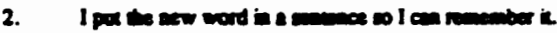

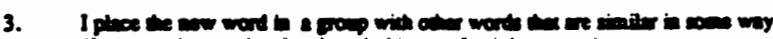

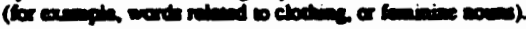

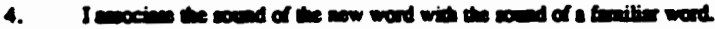

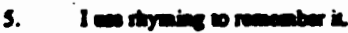

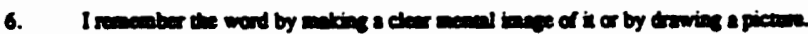

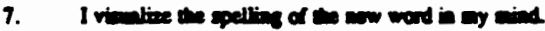

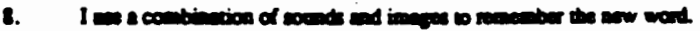

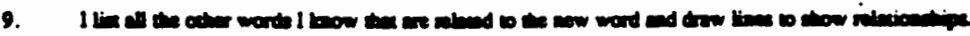

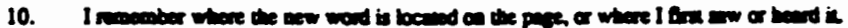

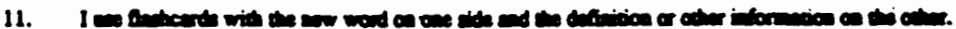

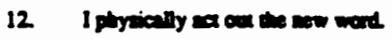




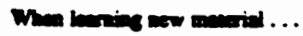

13. I rovier cien.

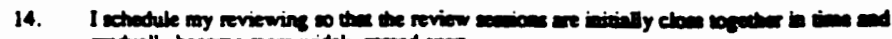

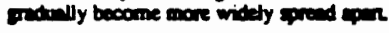

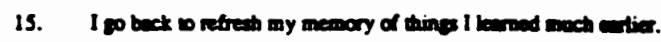

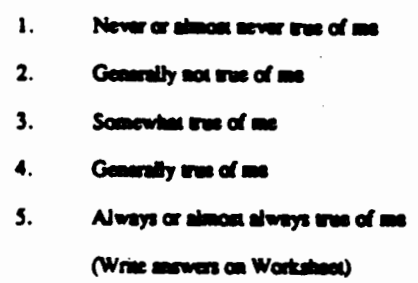

\section{ans}

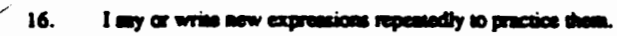

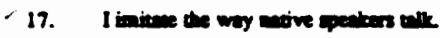

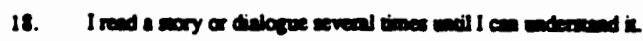

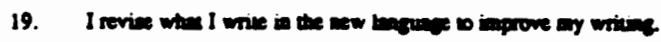

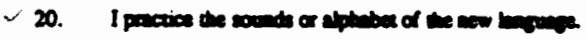

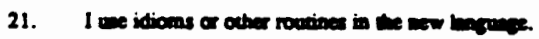

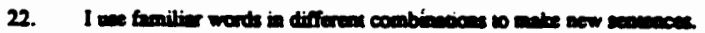

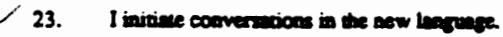

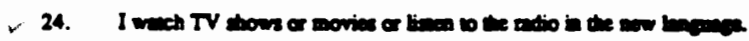

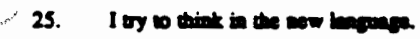

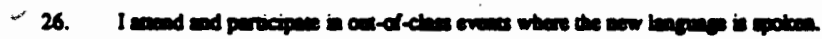

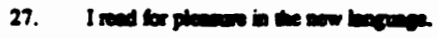

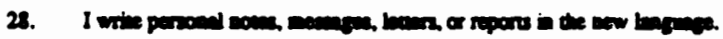

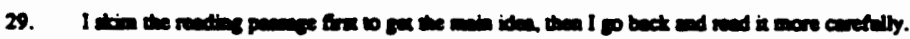

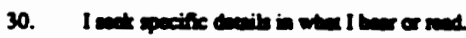

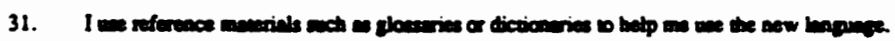

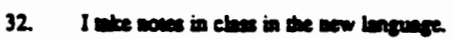

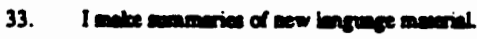

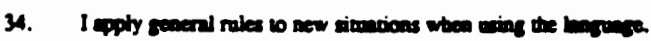

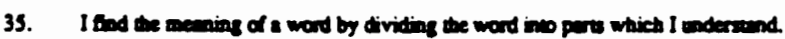

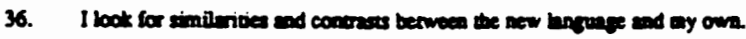

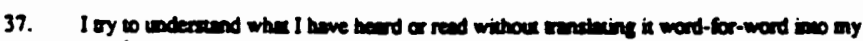
own ingure.

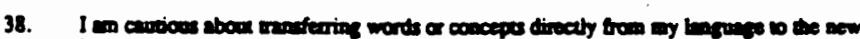
beriege.

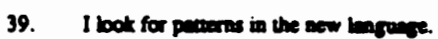


STRATEGY NNVENTORY FOR LANGUAGE LEARNING

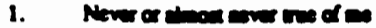

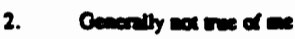 \\ 3. Somonten of of \\ 4. Coneriny ore of an

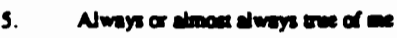

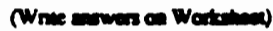

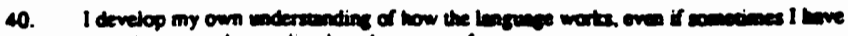

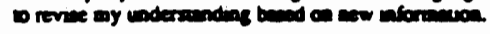

\title{
merc
}

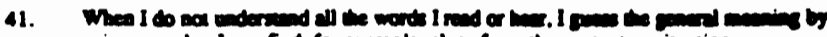

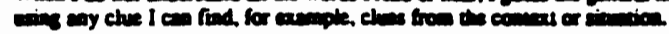

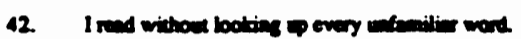

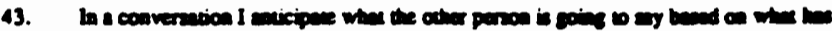

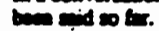

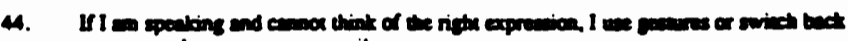

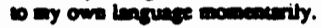

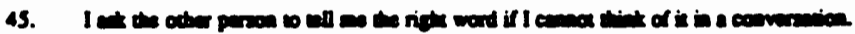

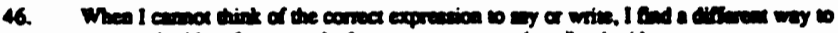

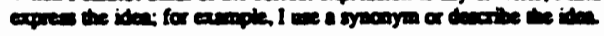

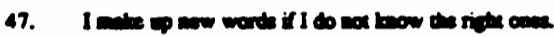

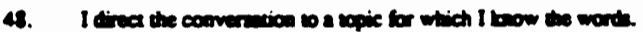

En

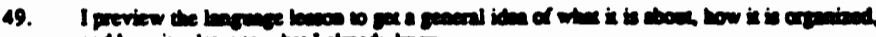

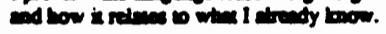

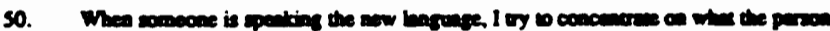

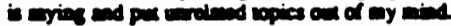

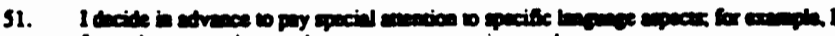

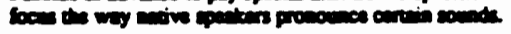

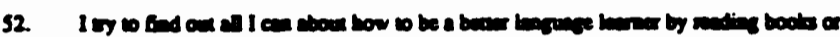

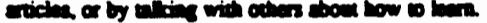

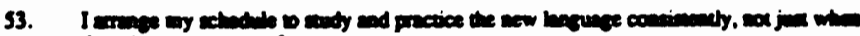
tres it be presen of a we

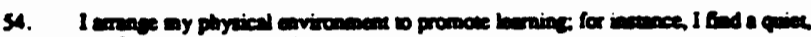
conforbble pace eroview.

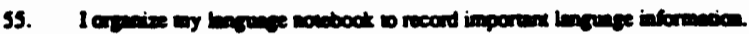

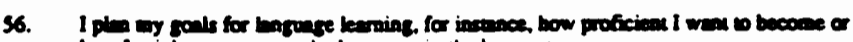

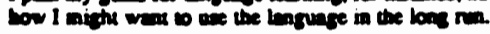


STAATEGY INVENTOAY FOR LANGUAGE LEARNING

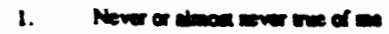 \\ 2. Ceaselly wat one of an \\ 3. Somewten tore of \\ 4. Goveriby une of ane

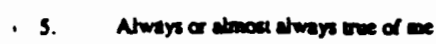 \\ (Wrice unwes on Wortingex)
}

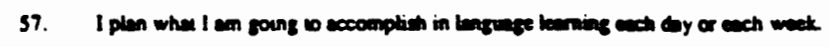

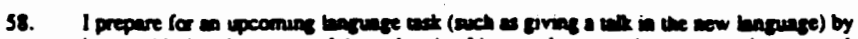

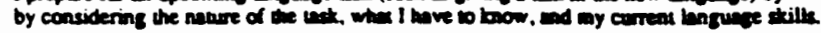

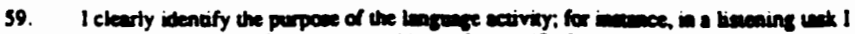

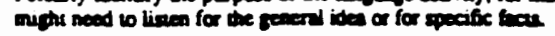

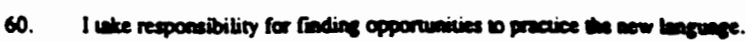

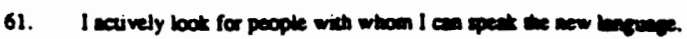

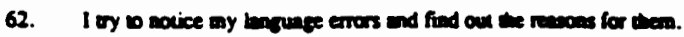

63. I leam trom my miserkes in wing the new bagure.

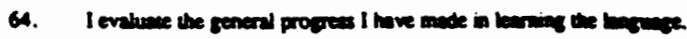

\title{
Das
}

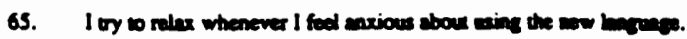

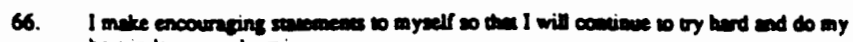
bea in binguare learing.

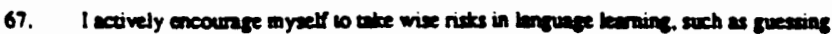

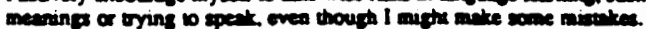

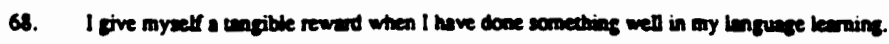

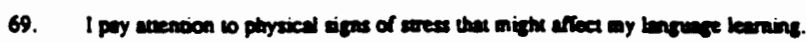

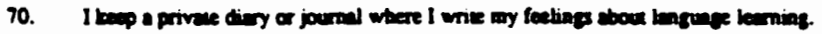

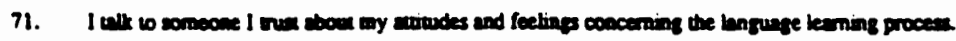

Bure

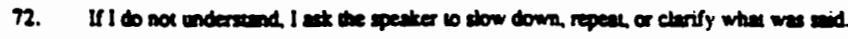

73. I wh oher pecple to verify the I huve understood or wid eomething correcaly.

74. I etc obler people wo conea my pronuncietion.

75. I watk with odher bengunge benness w procice, review, or thre informaion.

76. I hove a reguler langunge leming parser.

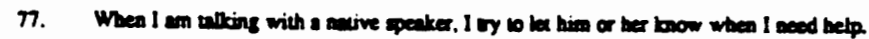

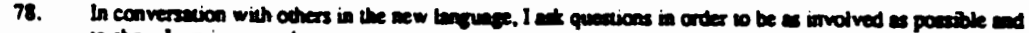
o show I en incresed.

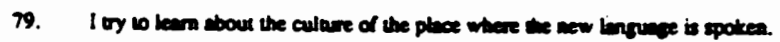

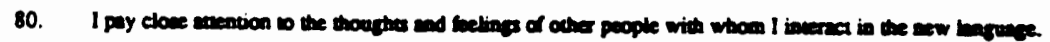


SILL

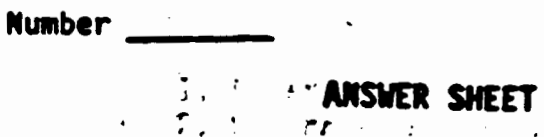

STRATEGIC INUEMTORY FOR LAMGUAGE LEARNING

(Version 5.1, c Rebecea Oxford, 1989)

For English Speakers Learning a New Language.

1. Never or almost never true of we.

2. Generally not true of $m$.

3. Somewhat true of $\mathrm{xe}$.

4. Generally true of $i$.

5. Always or almost always true of we.

EXAMPLE

1. 12345

\section{Part A}

1. 12345

2. 12345

3. 122345

4. 12345

5. 12345

sin $115=$

16. 12345

17. 12345

18. 12345

19. 12345

20. 122345

21. 12345

22. 12345

23. 122345

24. 12345

Son $125=$
6. 122345

7. 12345

8. 12345

9. 12345

10. 12345

\section{Part 8}

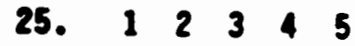

26. 12345

27. 12345

28. $12234 \quad 5$

29. 12345

30. 12345

31. 12345

32. 12345

33. $122 \quad 3 \quad 4 \quad 5$
11. 12345

12. $123 \quad 345$

13. 12345

14. 12345

15. 12345
33. 12345

34. 12345

35. 12345

36. 12345

37. 12345

38. 12545

39. $123 \quad 5$

40. 12345 
SILL

Number

1. Never or almost never true of me.

2. Generally not true of me.

3. Somewhat true of me.

4. Generally true of me.

5. Aiways or almost always true of me.

\section{Part C}

41. 12345

42. 122345

43. $122 \quad 3 \quad 4 \quad 5$

SUM $18=$

49. $12234 \quad 5$

50. 122345

51. $1234 \quad 5$

52. 11223015

53. $1122 \quad 3 \quad 4 \quad 5$

54. 1.2345

SuY $116=$

65. 122345

66. $122 \quad 3 \quad 4 \quad 5$

67. $122 \quad 3 \quad 4 \quad 5$

SUM $17=$

72. 122345

73. $122 \quad 3 \quad 4 \quad 5$

74. 122304

SUM $19=$
44. 12345

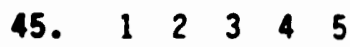

46. 122345

\section{Part D}

57. 122345

60. 1223445

56. 12345

61. 12345

57. 122345

62. $122 \quad 3 \quad 4 \quad 5$

58. 122345

63. 12345

59. $123 \quad 3 \quad 4 \quad 5$

64. 123345

\section{Part E}

68. 12345

70. $12 \begin{array}{llll}1 & 2 & 4 & 5\end{array}$

69. $123 \quad 45$

71. 121345

\section{Part $F$}

75. $12234 \quad 5$

78. 12345

76. $1 \begin{array}{lllll} & 2 & 3 & 4 & 5\end{array}$

79. 12345

77. 121345

80. I 2345 
APPENDIX B

SURVEY: RUSSIAN VERSION 


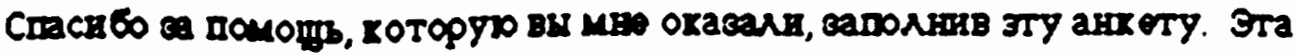

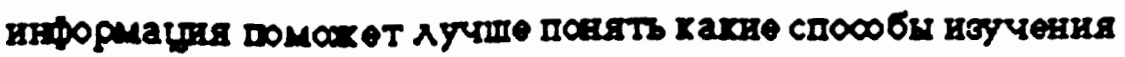

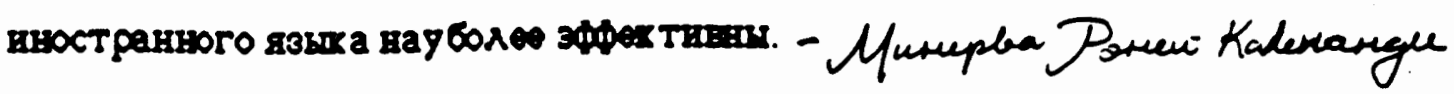

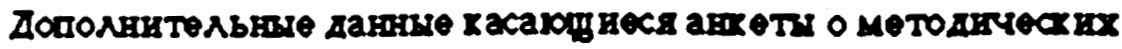

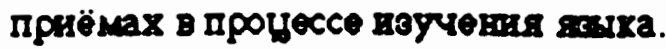

Corласnе

R, Drласен (согласва) участвовать в иоледованин, ьаправлөнном на изучение индивидуахьних прнёмов

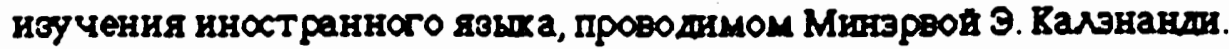

Я повнмаю, что исследсванпе подрезумевает заполнение авкеты С вопросами об иэученин дзика в тест методнческих приёмов в

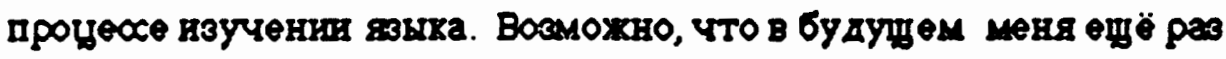
попросят повторнть тот хө Тест. Я поннмаю, что уель всследования -

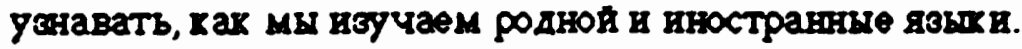

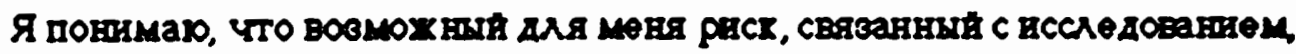

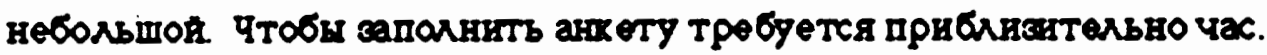

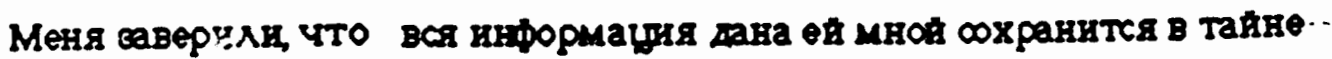
в, что личность всех уестнихов будет вензвестна.

Я понтмар, что моё участие добровольно сделано и, что я смоГу

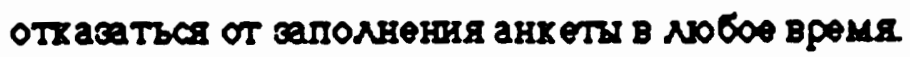

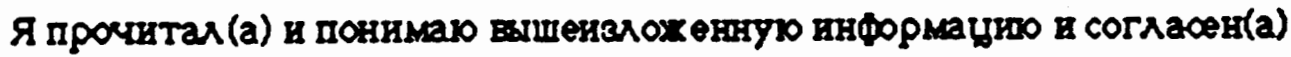
участвовать в всследованин. 
1. Box 100

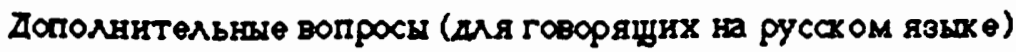

2. дата 3. Bospact

4. IIar

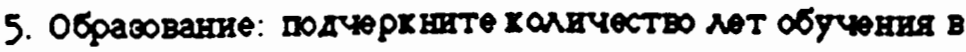

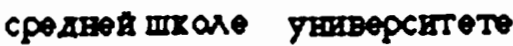
acrupartypo $9101112 \quad 1234$ $1234+$

6. POAнӧ вык

7. Ha xaxом gouxe вu robopriv apma?

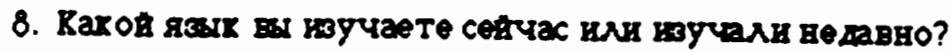

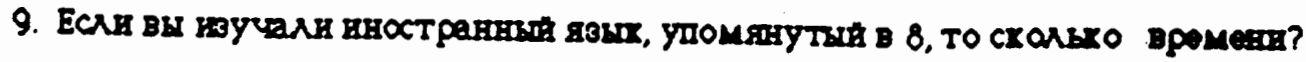

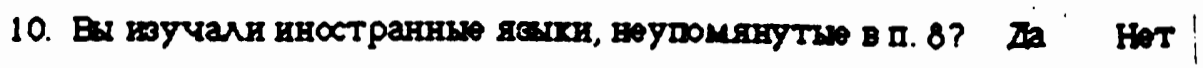

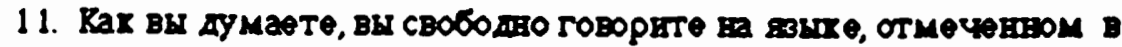

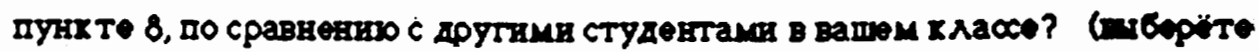

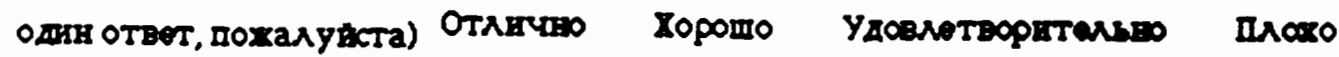

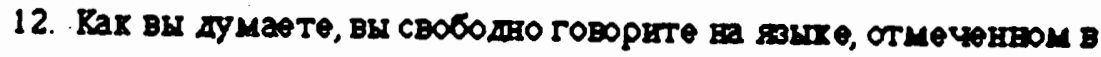
Пунх Те 8, по сраввенио с носителями этого докиа?

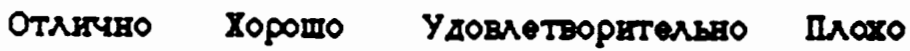

13. Ках ви считаете, вахво Ан развивать способность Говорить ва

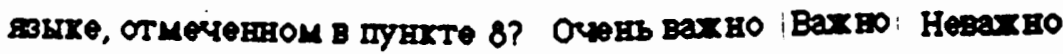

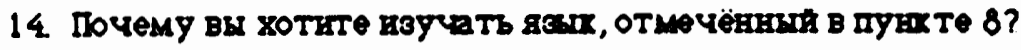

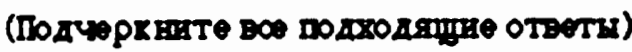

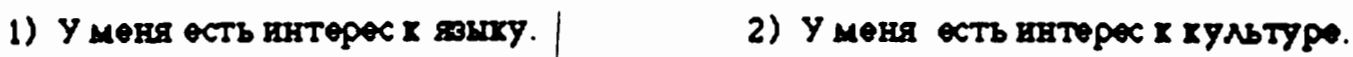

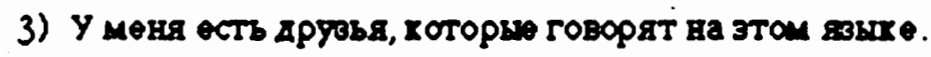

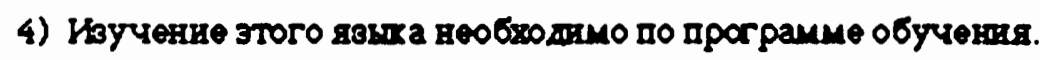

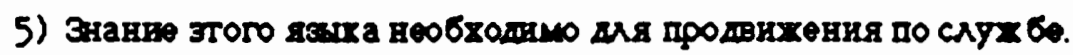

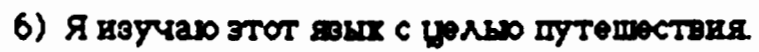

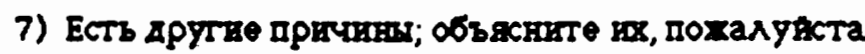

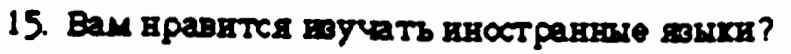
Ia $\mid$ HeT ।

16. Вақова, на ваш вогляд равитуја мехху методами иэучения

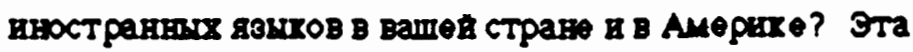
разнида мохет бать оцевев вама полохительна,

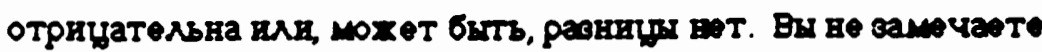

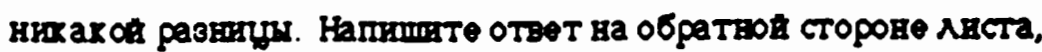
өски но хватает места здес. 


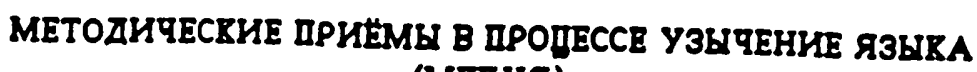
(MIII Yя)

Baprant 7.0

P. Orcyopa, 1989

\section{YRABAHRH}

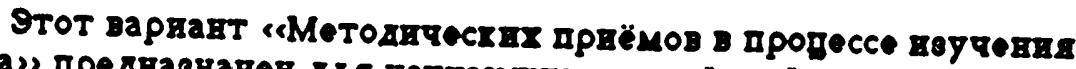

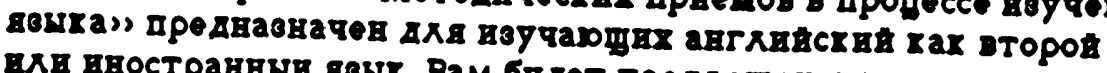

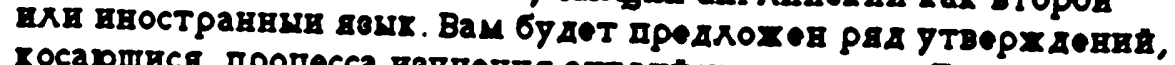

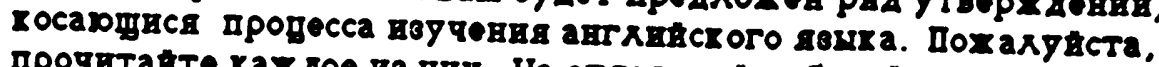

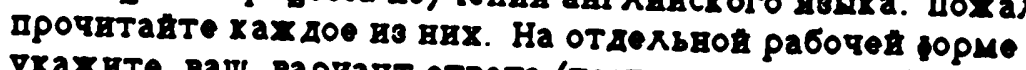

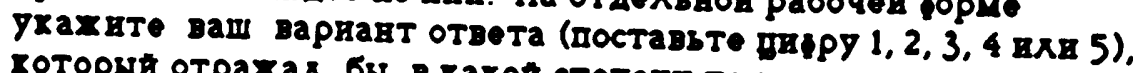

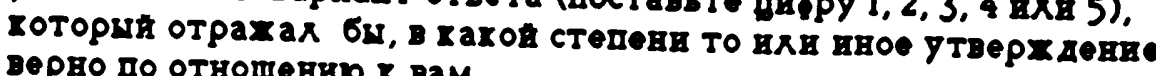
верно по отнотенио $x$ вам.

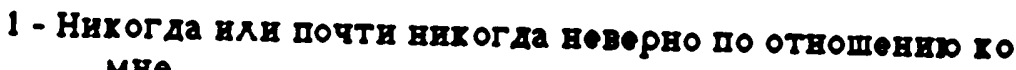
ure.

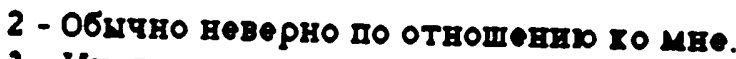

3 - Кногда верно по отношенH0 го мве.

4 - Обччно верно по отнотенто го мне.

5 - Всегда вкв почтв всегда верво по отвотевно го мве.

“Нихогда ихи почти внхогда веверво по отвотевно го мве" овначает, что рассматрвваемое ттверх денве ечень релхе верво по отнотевио 2 вам.

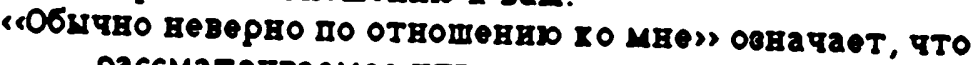
рассмат рнваемое 7 тверх денве верво менее чемв пеховине схучаев.

"НногАа верно по Отнотевно го мве" оевачает, чтО Утверх девие верно по отвотевио х вам повмерве

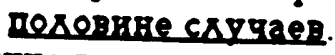

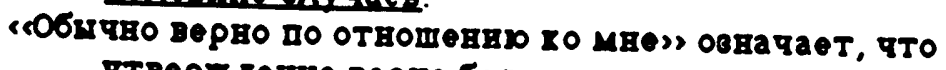
Гтверх денве верно бедее тем в пеховине схучаев.

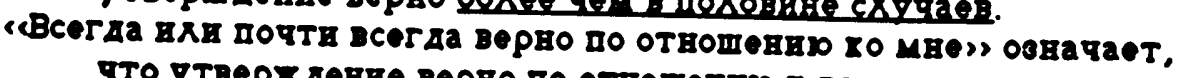

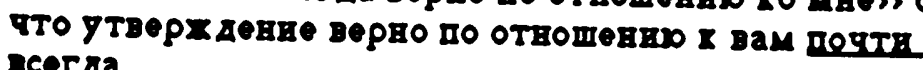
acersa.

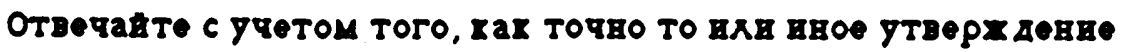
отрахает ваме поведевие. Не всходите вь ваших представленив О том, xax by

Имеtте В виду, पто ва предхагаемке утверх деввя в०

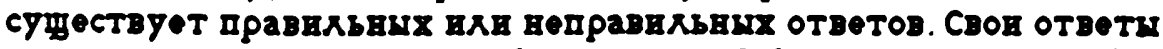

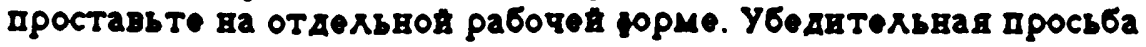

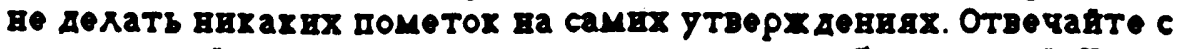
првемхемон дла вас схоростьр, ве допусхая вебрехвостен. Вах праввко, ва все ответи требуетсп ве более 20-30 мдвут. 
1. Я соотношу свои предшөствующие знания с иньорманиен, получаемон в продессе нзучения ангхинсх ого язиха.

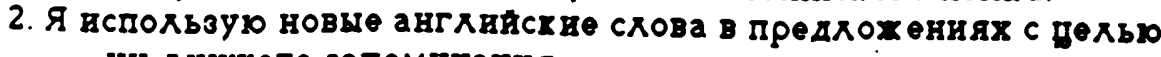
их хучшего запоминавия.

3. Я Связываљ звучание вового авглинсхого схова с определенним образом вхи хартинов, что помогает мве ЗаПОМнить этО СХОВО.

4. Я заучнвах ново ангхвнсхо слово путем мислевноГО представления ситуадин, В хоторон данвое слово моГло бы бить нспользовано.

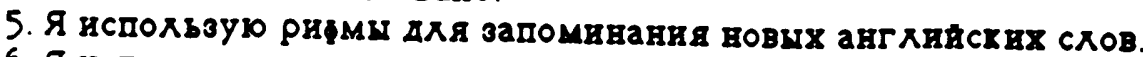

6. Я использую харточхи С ярхо в хрупно вапнсанними вовимв

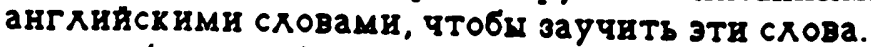

7. Я моторно (телесно) проигрнвау новое ангхннсхое слово.

8. Я часто повторяо пронденни матөрнах по ангхинсхому 8зиху

9. Я заучивах новуе анГхинскве слова ихи вцрахения путем запоминания их располохендя на стравиде, досхе вли Уरично вцвесхе.

10. Я несхохьхо раз проговарввах или прописиваб вовие англйсхне СХОва.

11. Я старајось говорить хах воснтехн язиха.

12. Я упрахняюсь в англднсхом пронзнотенни.

13. Я использую знахомуе авГхинсхне слова разлвчними cпособамz.

14.Я ининиирую беседу на авгхинсхом язихе.

15. Я смотрю төлевиднониче дередачи влв јильми ва анг хйсхом язихе.

16. Я читах ва ангхндсхом радн удовольствия.

17. Я пишу записхн, письма ихд дог Хади ва англинсхом.

18. Сначаха в бегхо просматривах англинск ин техст, затөм внвматехвно прочвтиваб его ещё раз.

19. Я старајсь обнарухить в родном язихе слова, похохне ва новие ангХинсхин СХОва.

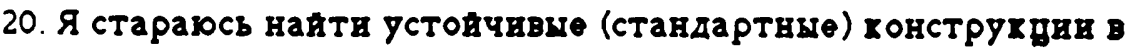
ангхйсхом язихе.

21. Я виясняю значение авгхинского схова, разбивая его ва части, значение хоторшх мне взвество.

22. Я старахсь не перевОднТЬ СЛОвО в СЛОво., прочнтавнон влд прослушаннон на авглдиском азике.

24. Я стараюсь угадать значенде незнахомых ангийсхих слов.

25. Когда, беседуя на англинском язихе, в не могу подобрать

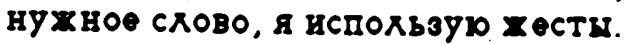

26. Я Придумквах схова, еслв ве моГу подобрать настоятео англинского слова.

27. Я читаю по-анГХинсхв ве вцясняя значения хах дого попадајџегося незвах омого слова. 


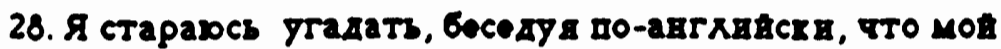
cobece 4 Hinx cobrpaetcr craeatz.

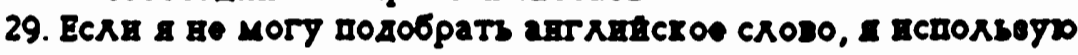

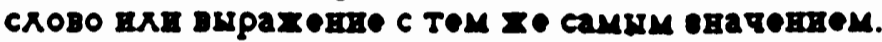

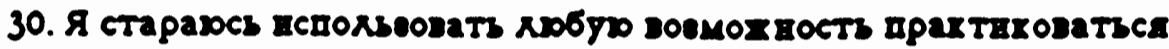
- amrरratczon.

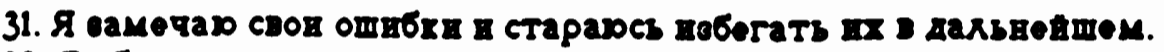

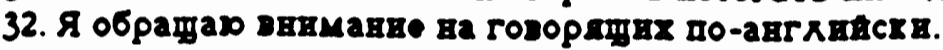

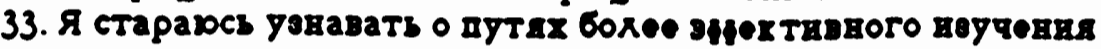
sovra.

34. Я пканируо своё времд тахвм обраsом, чтоби вметз

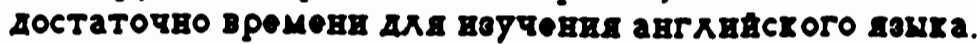

35. Я старарсь ванти хрдеt, с готоримв мохво бмхо би по0бщатьсв ва авгхвнском.

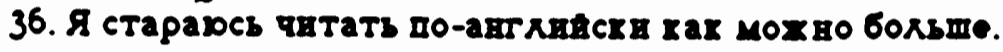

37. Я ставхо дснуе в опредехевнуе gехв \ деке YCове pшевCт

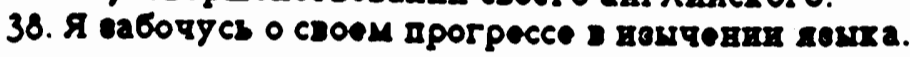

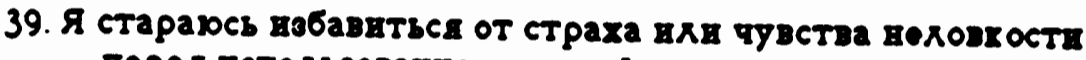

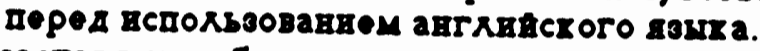

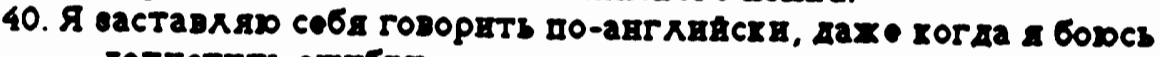
40IYCTaTb OmE6xy.

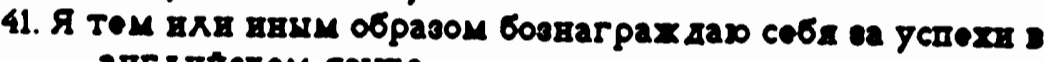

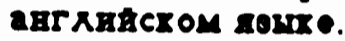

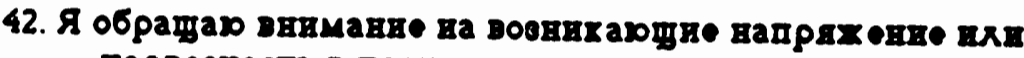

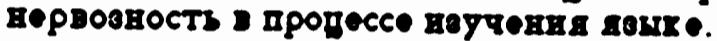

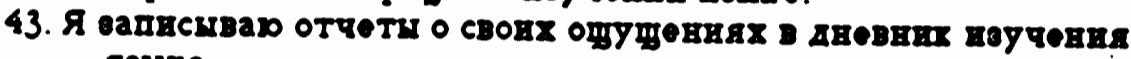
sosx a.

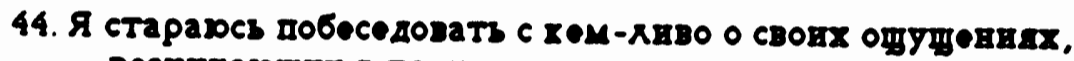

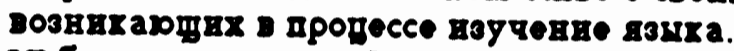

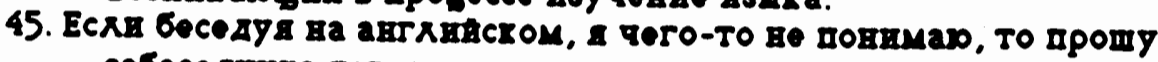

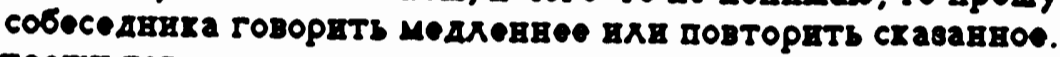

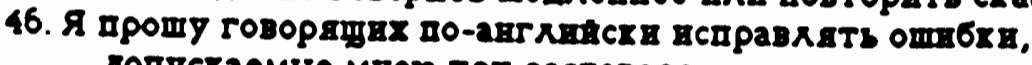
допустаемие мвор прв растоворе.

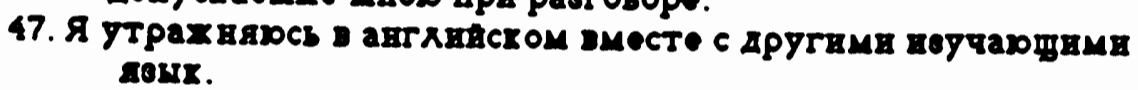

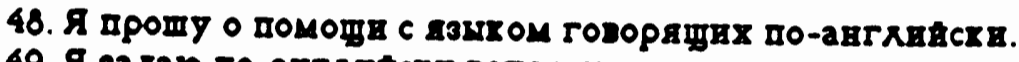

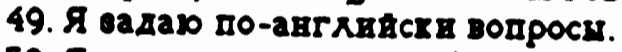

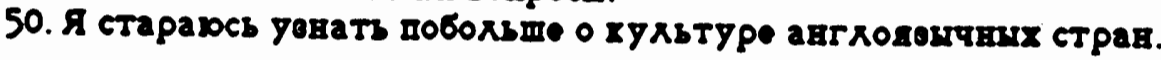


РАБОपАЯ ФОРМА ДЛЯ ОТВЕТОВ И ПОДСЧЕТА ОЧКОВ ДЛЯ МППНЯ Bepcra 7.0

P. Ox ç०pд, 1989

OBPAЗED

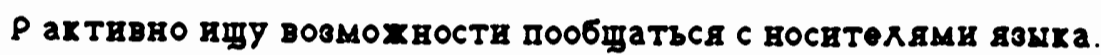

На этон стравиде просто впишите «Х» в прочерх под УТверх дөнием, хоторое наялучшим образом опискваөт, что ви реально дехаете в настояџее время хасательно нзучения ангхйсхого язиха.

\begin{tabular}{|c|c|c|c|c|}
\hline 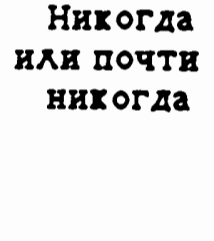 & 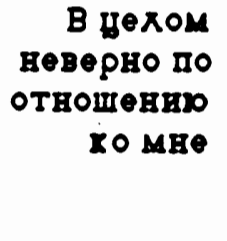 & 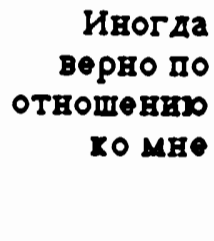 & 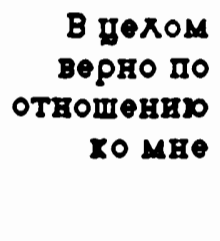 & 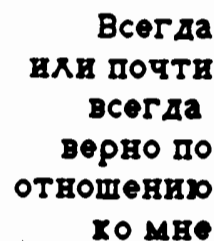 \\
\hline 1 & 2 & 3 & 4 & \\
\hline
\end{tabular}

ОТветив на вишезаданиц вопрос, ву запохвнхи образед ответа.

Теперь дох дитесь сигваха преподавателя х продолхенио paботи. Отвеqаसте на вопроси бистро, но вАумчнво в ахху ратно. Начиная с пунхта вомер 1, отмечанте ваши ответи на рабочен ऽорме. 
KOA Дата

1. Номера прочерхов (_-_) соответствуот вомерам утверх денин в мппия.

2. Запишуте ваш ответ ва хах АнЕ пувхт (заполнуте хах дин

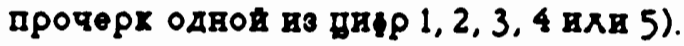

पACTB A पACTB B पACTBC पACTBD पACTBE पACTB F

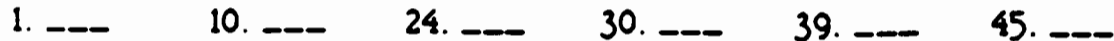

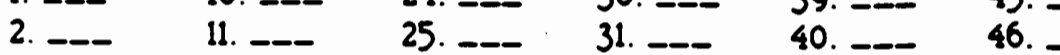

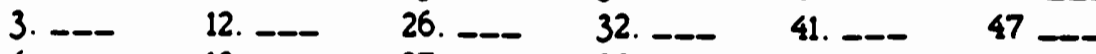

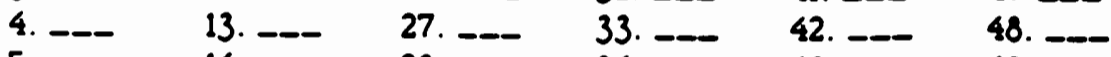

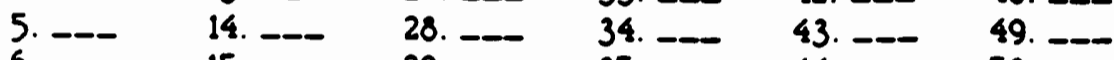

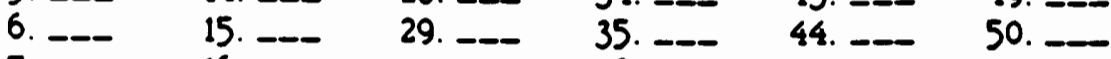

7. - 16. - 36 36.

8. -- 17. -- $37 .-$

9. -- 18. -- $\quad 38 .--$

19. - -

20. - -

21. --

22. - -

23. - -

СУМMЫ: (не нухно пнсать внчего)

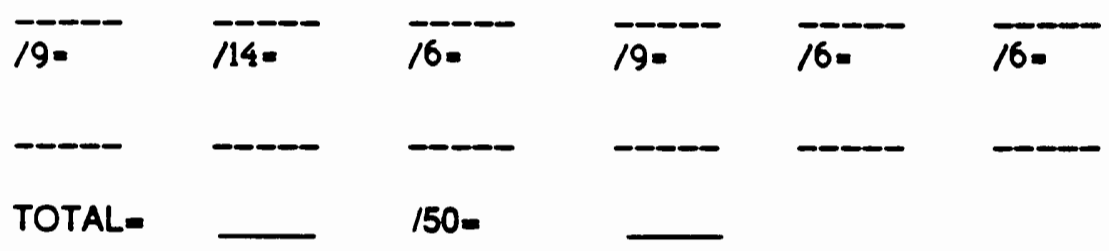


APPENDIX C

RAW SCORES 


\begin{tabular}{|c|c|c|c|c|c|c|c|}
\hline Case & PartA & PartB & Partc & PartD & PartE & PartF & Total \\
\hline Group 1 & 51 & 83 & 26 & 56 & 24 & & \\
\hline 2 & 41 & 83 & 29 & 64 & 19 & 35 & 271 \\
\hline 3 & 55 & 102 & 30 & 56 & 23 & 36 & 302 \\
\hline 4 & 48 & 95 & 29 & 55 & 22 & 35 & 284 \\
\hline 5 & 48 & 75 & 25 & 62 & 19 & 36 & 265 \\
\hline 6 & 42 & 98 & 26 & 60 & 21 & 35 & 282 \\
\hline 7 & 49 & 83 & 29 & 57 & 20 & 29 & 267 \\
\hline 8 & 50 & 109 & 32 & 62 & 22 & 39 & 314 \\
\hline 9 & 37 & 98 & 31 & 58 & 13 & 31 & 268 \\
\hline \multicolumn{8}{|l|}{ Group 2} \\
\hline 10 & 45 & 98 & 33 & 55 & 20 & 33 & 284 \\
\hline 11 & 47 & 83 & 28 & 48 & 25 & 35 & 266 \\
\hline 12 & 48 & 106 & 27 & 63 & 24 & 33 & 301 \\
\hline 13 & 56 & 108 & 35 & 56 & 24 & 33 & 301 \\
\hline 14 & 24 & 77 & 32 & 55 & 20 & 31 & 244 \\
\hline 15 & 46 & 92 & 30 & 40 & 19 & 32 & 254 \\
\hline 16 & 58 & 104 & 30 & 60 & 19 & 34 & 305 \\
\hline 17 & 41 & 86 & 30 & 51 & 17 & 25 & 250 \\
\hline 18 & 32 & 97 & 28 & 51 & 17 & 24 & 249 \\
\hline 19 & 41 & 94 & 31 & 54 & 20 & 36 & 276 \\
\hline 20 & 44 & 83 & 31 & 60 & 23 & 40 & 281 \\
\hline 21 & 51 & 87 & 30 & 55 & 14 & 33 & 270 \\
\hline 22 & 40 & 84 & 31 & 52 & 27 & 32 & 266 \\
\hline 23 & 42 & 99 & 34 & 41 & 12 & 26 & 254 \\
\hline 24 & 45 & 91 & 28 & 59 & 16 & 34 & 273 \\
\hline 25 & 35 & 72 & 27 & 43 & 17 & 34 & 228 \\
\hline 26 & 46 & 85 & 32 & 37 & 16 & 29 & 245 \\
\hline 27 & 48 & 83 & 29 & 66 & 21 & 32 & 279 \\
\hline 28 & 54 & 93 & 33 & 52 & 16 & 38 & 286 \\
\hline 29 & 39 & 68 & 20 & 50 & 22 & 27 & 226 \\
\hline 30 & 39 & 70 & 22 & 44 & 14 & 30 & 219 \\
\hline 31 & 42 & 87 & 29 & 54 & 16 & 35 & 263 \\
\hline 32 & 27 & 65 & 18 & 38 & 18 & 26 & 192 \\
\hline 33 & 55 & 110 & 24 & 70 & 27 & 34 & 320 \\
\hline 34 & 42 & 99 & 37 & 67 & 25 & 39 & 309 \\
\hline 35 & 52 & 88 & 33 & 52 & 20 & 22 & 267 \\
\hline \multicolumn{8}{|l|}{ Group 3} \\
\hline 36 & 51 & 108 & 34 & 66 & 21 & 39 & 319 \\
\hline 37 & 44 & 81 & 25 & 39 & 17 & 30 & 236 \\
\hline 38 & 42 & 87 & 29 & 52 & 22 & 29 & 261 \\
\hline 39 & 44 & 78 & 30 & 53 & 19 & 31 & 255 \\
\hline 40 & 53 & 97 & 31 & 64 & 18 & 37 & 300 \\
\hline
\end{tabular}


(Raw Scores, English Version, continued)

Case PartA PartB PartC PartD PartE PartF Total

$\begin{array}{llllllll}41 & 55 & 98 & 31 & 66 & 23 & 37 & 310 \\ 42 & 61 & 102 & 33 & 75 & 29 & 37 & 337 \\ 43 & 41 & 99 & 34 & 51 & 26 & 33 & 284 \\ 44 & 44 & 61 & 23 & 51 & 20 & 32 & 231 \\ 45 & 36 & 99 & 34 & 41 & 17 & 32 & 259 \\ 46 & 44 & 96 & 33 & 56 & 18 & 28 & 275 \\ 47 & 52 & 86 & 32 & 49 & 20 & 26 & 265\end{array}$


RAW SCORES: RUSSIAN VERSION

\begin{tabular}{|c|c|c|c|c|c|c|c|}
\hline Case & $\underline{\text { PartA }}$ & $\underline{\text { PartB }}$ & PartC & PartD & PartE & PartF & Total \\
\hline \multicolumn{8}{|l|}{$\overline{\text { Group } 1}$} \\
\hline 1 & 12 & 23 & 9 & 18 & 9 & 12 & 83 \\
\hline 2 & 30 & 43 & 26 & 40 & 14 & 23 & 176 \\
\hline 3 & 27 & 50 & 26 & 37 & 21 & 24 & 185 \\
\hline 4 & 24 & 36 & 20 & 24 & 18 & 20 & 142 \\
\hline 5 & 30 & 40 & 20 & 33 & 20 & 20 & 163 \\
\hline 6 & 31 & 42 & 28 & 39 & 24 & 23 & 187 \\
\hline 7 & 31 & 39 & 28 & 39 & 24 & 23 & 184 \\
\hline 8 & 30 & 40 & 24 & 32 & 19 & 24 & 169 \\
\hline 9 & 30 & 38 & 27 & 33 & 23 & 23 & 174 \\
\hline \multicolumn{8}{|l|}{ Group 2} \\
\hline 10 & 30 & 36 & 20 & 36 & 16 & 24 & 162 \\
\hline 11 & 26 & 49 & 21 & 36 & 18 & 23 & 173 \\
\hline 12 & 30 & 42 & 17 & 37 & 18 & 21 & 165 \\
\hline 13 & 30 & 48 & 26 & 32 & 24 & 29 & 189 \\
\hline 14 & 31 & 37 & 17 & 34 & 13 & 20 & 152 \\
\hline 15 & 25 & 42 & 25 & 40 & 27 & 28 & 188 \\
\hline 16 & 32 & 44 & 22 & 36 & 24 & 24 & 182 \\
\hline 17 & 30 & 50 & 22 & 36 & 20 & 24 & 182 \\
\hline 18 & 32 & 44 & 22 & 36 & 24 & 24 & 182 \\
\hline 19 & 32 & 40 & 22 & 36 & 22 & 24 & 176 \\
\hline 20 & 13 & 55 & 13 & 39 & 18 & 29 & 167 \\
\hline 21 & 24 & 42 & 18 & 36 & 20 & 24 & 164 \\
\hline \multicolumn{8}{|l|}{ Group 3} \\
\hline 22 & 31 & 52 & 22 & 39 & 12 & 22 & 178 \\
\hline 23 & 35 & 51 & 23 & 36 & 19 & 27 & 191 \\
\hline 24 & 40 & 58 & 29 & 44 & 30 & 30 & 231 \\
\hline 25 & 31 & 49 & 22 & 39 & 10 & 30 & 183 \\
\hline 26 & 33 & 60 & 26 & 41 & 18 & 29 & 207 \\
\hline 27 & 24 & 36 & 18 & 24 & 12 & 16 & 142 \\
\hline 28 & 29 & 42 & 26 & 35 & 18 & 25 & 170 \\
\hline 29 & 26 & 42 & 24 & 24 & 18 & 16 & 150 \\
\hline 30 & 17 & 33 & 19 & 31 & 14 & 30 & 144 \\
\hline 31 & 32 & 46 & 24 & 35 & 17 & 24 & 178 \\
\hline 32 & 29 & 55 & 23 & 41 & 14 & 25 & 187 \\
\hline 33 & 24 & 48 & 18 & 36 & 18 & 22 & 166 \\
\hline 34 & 36 & 44 & 16 & 36 & 18 & 18 & 168 \\
\hline 35 & 27 & 40 & 16 & 34 & 12 & 20 & 149 \\
\hline 36 & 34 & 49 & 29 & 39 & 23 & 28 & 202 \\
\hline 37 & 31 & 44 & 28 & 36 & 19 & 24 & 182 \\
\hline 38 & 31 & 45 & 20 & 36 & 24 & 29 & 185 \\
\hline 39 & 31 & 43 & 20 & 36 & 24 & 30 & 184 \\
\hline 40 & 34 & 46 & 21 & 43 & 15 & 27 & 186 \\
\hline
\end{tabular}


(Raw Scores, Russian Version, cont.)

Case PartA PartB PartC PartD PartE PartF Total

$\begin{array}{llllllll}41 & 33 & 49 & 26 & 35 & 22 & 24 & 189 \\ 42 & 33 & 48 & 21 & 43 & 15 & 27 & 187 \\ 43 & 26 & 37 & 17 & 31 & 18 & 22 & 181 \\ 44 & 32 & 47 & 28 & 40 & 21 & 26 & 194 \\ 45 & 31 & 47 & 27 & 43 & 14 & 25 & 187 \\ 46 & 27 & 43 & 21 & 41 & 16 & 25 & 173 \\ 47 & 22 & 24 & 11 & 26 & 18 & 11 & 117\end{array}$


APPENDIX D

LANGUAGE LEARNING STRATEGIES 
INDIRECT STRATEGIES

(Meracognitive, Affective, and Social Strategies)

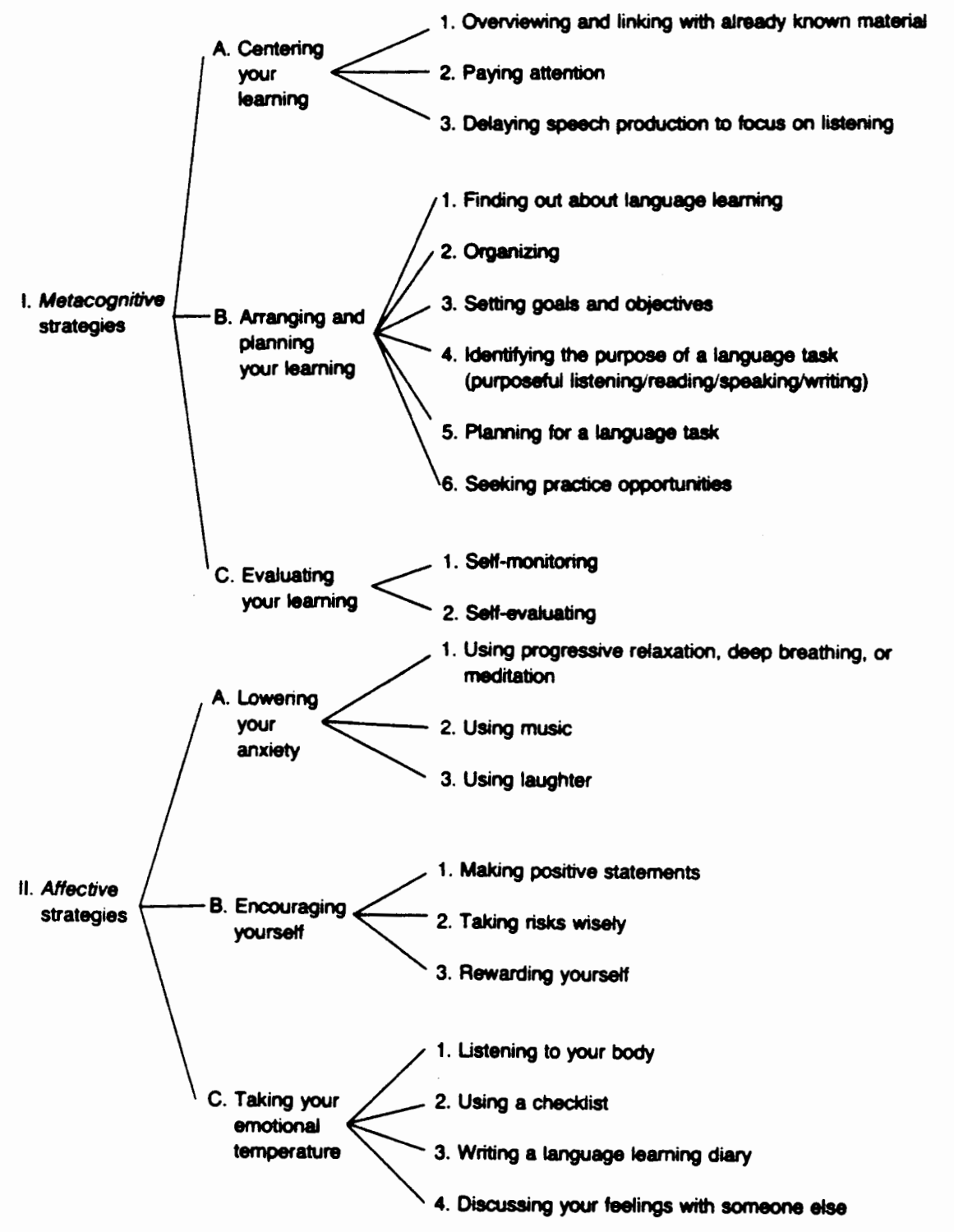

C. Empathizing 1. Doveloping cultural understanding with others 


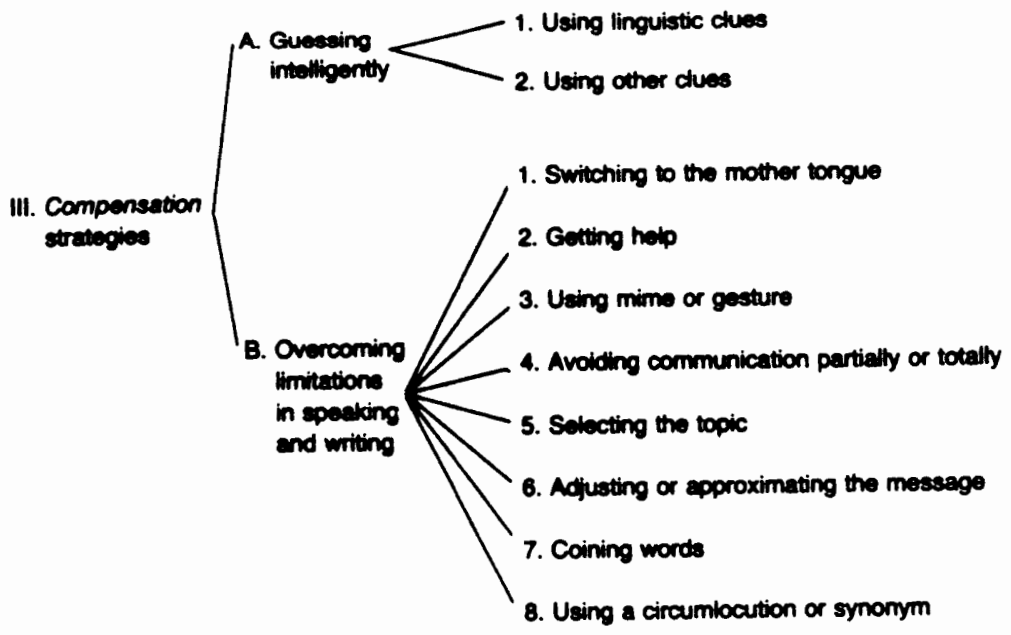




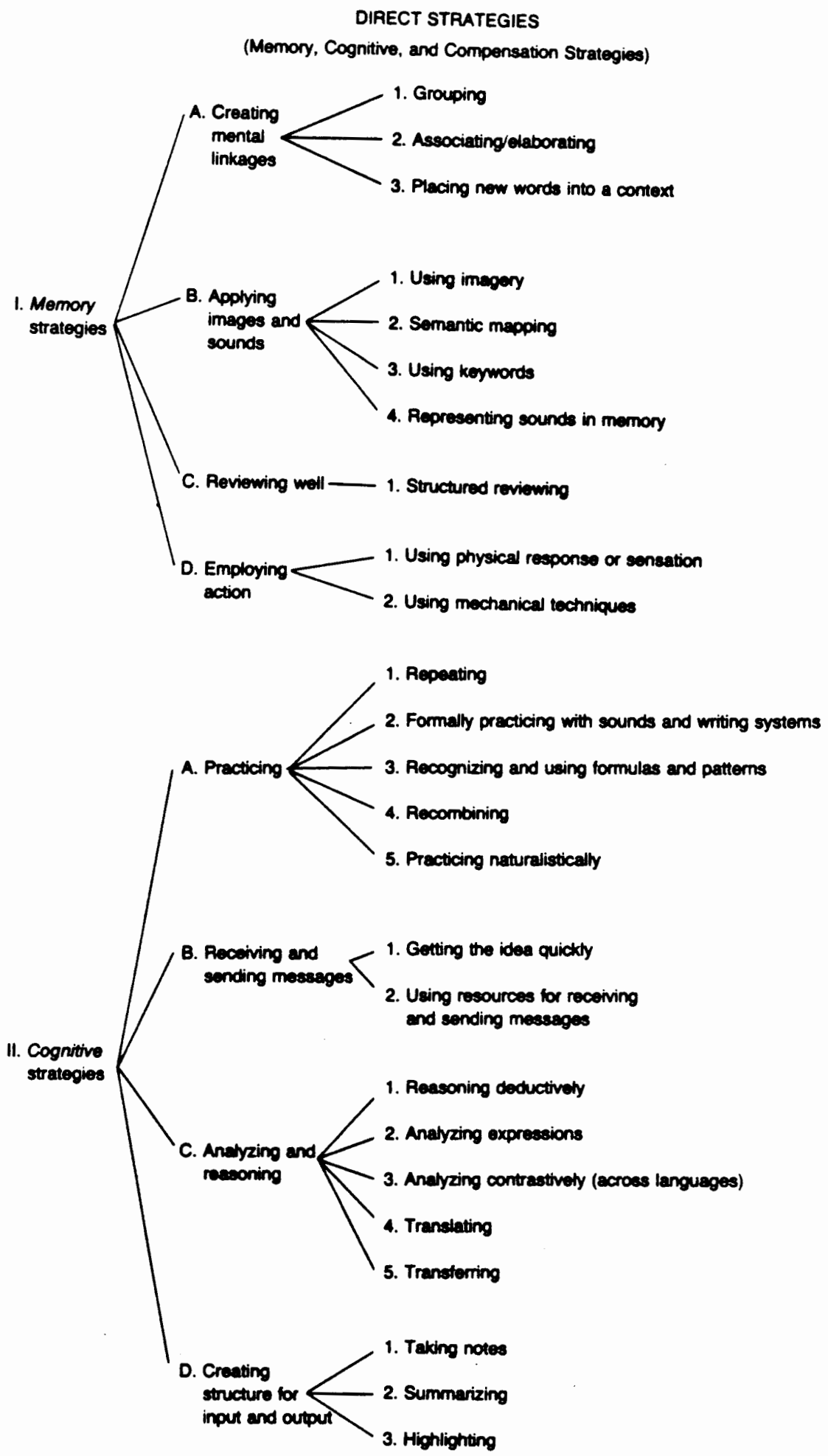

